\title{
Variable sediment oxygen uptake in response to dynamic forcing
}

\author{
Lee D. Bryant,a, ${ }^{\text {* }}$ Claudia Lorrai, b,c Daniel F. McGinnis, ${ }^{\mathrm{b}, 1}$ Andreas Brand,b,2 Alfred Wüest, b,c and \\ John C. Littlea \\ a Civil and Environmental Engineering, Virginia Tech, Blacksburg, Virginia \\ bEawag (Swiss Federal Institute of Aquatic Science and Technology), Surface Waters - Research and Management, Kastanienbaum, \\ Switzerland \\ c Institute of Biogeochemistry and Pollutant Dynamics, ETH Zurich, Zurich, Switzerland
}

\begin{abstract}
Seiche-induced turbulence and the vertical distribution of dissolved oxygen above and within the sediment were analyzed to evaluate the sediment oxygen uptake rate $\left(J_{\mathrm{O}_{2}}\right)$, diffusive boundary layer thickness $\left(\delta_{\mathrm{DBL}}\right)$, and sediment oxic zone depth $\left(z_{\max }\right)$ in situ. High temporal-resolution microprofiles across the sediment-water interface and current velocity data within the bottom boundary layer in a medium-sized mesotrophic lake were obtained during a 12-h field study. We resolved the dynamic forcing of a full 8-h seiche cycle and evaluated $J_{\mathrm{O}_{2}}$ from both sides of the sediment-water interface. Turbulence (characterized by the energy dissipation rate, $\varepsilon$ ), the vertical distribution of dissolved oxygen across the sediment-water interface (characterized by $\delta_{\mathrm{DBL}}$ and $z_{\mathrm{max}}$ ), $J_{\mathrm{O}_{2}}$, and the sediment oxygen consumption rate $\left(R_{\mathrm{O}_{2}}\right)$ are all strongly correlated in our freshwater system. Seicheinduced turbulence shifted from relatively active $\left(\varepsilon=1.2 \times 10^{-8} \mathrm{~W} \mathrm{~kg}^{-1}\right)$ to inactive $\left(\varepsilon=7.8 \times 10^{-12} \mathrm{~W} \mathrm{~kg}{ }^{-1}\right)$. In response to this dynamic forcing, $\delta_{\mathrm{DBL}}$ increased from $1.0 \mathrm{~mm}$ to the point of becoming undefined, $z_{\text {max }}$ decreased from 2.2 to $0.3 \mathrm{~mm}$ as oxygen was depleted from the sediment, and $J_{\mathrm{O}_{2}}$ decreased from 7.0 to $1.1 \mathrm{mmol} \mathrm{m}^{-2} \mathrm{~d}^{-1}$ over a time span of hours. $J_{\mathrm{O}_{2}}$ and oxygen consumption were found to be almost equivalent (within $\sim 5 \%$ and thus close to steady state), with $R_{\mathrm{O}_{2}}$ adjusting rapidly to changes in $J_{\mathrm{O}_{2}}$. Our results reveal the transient nature of sediment oxygen uptake and the importance of accurately characterizing turbulence when estimating $J_{\mathrm{O}_{2}}$.
\end{abstract}

Dissolved oxygen $\left(\mathrm{O}_{2}\right)$ is one of the most critical ecological parameters affecting natural aquatic systems with benthic diversity, ecosystem health, and overall water quality all negatively influenced by depleted $\mathrm{O}_{2}$ levels (Wetzel 2001; Stachowitsch et al. 2007). The amount of $\mathrm{O}_{2}$ taken up by the sediment largely governs $\mathrm{O}_{2}$ depletion in stratified waters with organic-rich sediment (Bouldin 1968; Veenstra and Nolen 1991). Sediment $\mathrm{O}_{2}$ uptake is a function of both physical limitations on $\mathrm{O}_{2}$ transfer to the sediment and sediment $\mathrm{O}_{2}$ consumption processes (Jørgensen and Boudreau 2001). Resolving the vertical distribution of $\mathrm{O}_{2}$ at the sediment-water interface (SWI) allows for the quantification of the sediment $\mathrm{O}_{2}$ uptake flux $\left(J_{\mathrm{O}_{2}}\right)$, which is a fundamental parameter for the characterization of $\mathrm{O}_{2}$ dynamics in aquatic systems (Wetzel 2001). Consequently, considerable effort has been devoted to elucidating the water-side and sedimentside factors controlling sediment $\mathrm{O}_{2}$ uptake in freshwater and marine systems (Bouldin 1968; Jørgensen and Revsbech 1985; Boudreau 2001).

Molecular diffusion typically becomes the controlling transport process for dissolved species (e.g., $\mathrm{O}_{2}$ ) at approximately $1 \mathrm{~mm}$ above the SWI in nonadvective systems (e.g., cohesive freshwater and marine sediment; Jørgensen and Revsbech 1985; Røy et al. 2004). This

*Corresponding author: lebryan1@vt.edu

Present address:

${ }^{1}$ IFM-GEOMAR, Leibniz Institute of Marine Sciences, RD2 Marine Biogeochemistry, Kiel, Germany

2 Civil and Environmental Engineering, University of California, Berkeley millimeter-scale region immediately above the SWI is referred to as the diffusive boundary layer (DBL; Jørgensen and Revsbech 1985). Diffusion through the DBL is often the rate-limiting step restricting the supply of $\mathrm{O}_{2}$ to the sediment in systems (e.g., lakes) where steep gradients occur at the SWI (Jørgensen and Revsbech 1985; Wüest and Lorke 2003). $\mathrm{O}_{2}$ transport to the SWI is driven by the concentration gradient in the DBL and is therefore a function of the thickness of the DBL $\left(\delta_{\mathrm{DBL}}\right)$, which is controlled by turbulent mixing in the bottom boundary layer (BBL), and $\mathrm{O}_{2}$ concentrations within the bulk BBL $\left(C_{\text {bulk }}\right)$ and at the SWI $\left(C_{\mathrm{SWI}}\right)$, as depicted in Fig. 1. Upon reaching the sediment, $\mathrm{O}_{2}$ is used for various biogeochemical processes (e.g., benthic organic matter mineralization and oxidation of reduced compounds) within the sediment oxic zone (quantified by depth $z_{\text {max }}$; Fig. 1). A balance between the rate at which $\mathrm{O}_{2}$ is supplied to the sediment, quantified by flux $J_{\mathrm{O}_{2}}\left(\mathrm{mmol} \mathrm{m} \mathrm{m}^{-2} \mathrm{~d}^{-1}\right)$, and the rate at which $\mathrm{O}_{2}$ is consumed within the sediment, quantified by the $\mathrm{O}_{2}$ consumption rate $\left(R_{\mathrm{O}_{2}}\right)$, which may be defined volumetrically $\left(R_{\mathrm{O}_{2}} ; \mathrm{mmol} \mathrm{m} \mathrm{m}^{-3} \mathrm{~d}^{-1}\right)$ or areally $\left(R_{\mathrm{O}_{2} a}\right.$; $\mathrm{mmol} \mathrm{m} \mathrm{m}^{-2} \mathrm{~d}^{-1}$ ), establishes the extent of the sediment oxic zone (Jørgensen and Boudreau 2001; Higashino et al. 2004). It is important to note that $R_{\mathrm{O}_{2}}$ describes the use of available $\mathrm{O}_{2}$ supplied to the sediment rather than the potential sediment $\mathrm{O}_{2}$ demand (PSOD), which is often evaluated as a constant volumetric $\mathrm{O}_{2}$ consumption rate. PSOD is a function of available electron acceptors in the sediment. While $R_{\mathrm{O}_{2} v}$ may approach PSOD in systems where $R_{\mathrm{O}_{2} v}$ controls $\mathrm{O}_{2}$ diffusion at the SWI (e.g., marine sediment), PSOD would be much greater than $R_{\mathrm{O}_{2} v}$ in highly organic, transport-limited systems (e.g., lake sedi- 


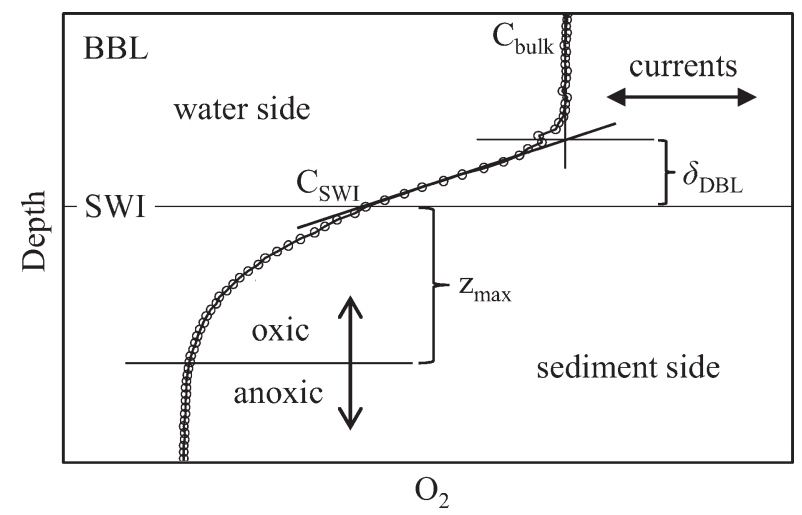

Fig. 1. The key components of a dissolved oxygen $\left(\mathrm{O}_{2}\right)$ profile are defined, illustrating the relationship between seiching, turbulent mixing, and the vertical distribution of $\mathrm{O}_{2}$ on both sides of the sediment-water interface (SWI; modified from Jørgensen and Revsbech 1985). Water-side components include the bottom boundary layer (BBL), the diffusive boundary layer (of thickness $\left.\delta_{\mathrm{DBL}}\right)$, and $\mathrm{O}_{2}$ concentrations in the BBL $\left(C_{\text {bulk }}\right)$ and at the SWI $\left(C_{\mathrm{SWI}}\right)$. On the sediment side, $z_{\max }$ is the depth of the sediment oxic zone.

ment; Wüest and Lorke 2003). Furthermore, while $R_{\mathrm{O}_{2} v}$ may be strongly influenced by $J_{\mathrm{O}_{2}}$, PSOD is a relatively inherent property unaffected by short-term variations in $\mathrm{O}_{2}$ availability.

Turbulence in the BBL (e.g., due to internal currents forced by wind or tide) has a direct effect on $\mathrm{O}_{2}$ transport to the sediment and thus also influences $\mathrm{O}_{2}$ consumption processes within the sediment. Significant insight has been gained from theoretical studies on how turbulence-induced variations in $\delta_{\mathrm{DBL}}$ affect $\mathrm{O}_{2}$ uptake (Higashino et al. 2004, 2008), the relative contributions of $\mathrm{O}_{2}$-consuming processes (Glud et al. 2007; Brand et al. 2009), and sediment microbial activity (Gantzer and Stefan 2003; Higashino and Stefan 2005). Rapid changes in $\delta_{\mathrm{DBL}}$ in response to dynamic forcing have been observed both in the laboratory (Mackenthun and Stefan 1998; Røy et al. 2004; O’Connor and Hondzo 2008) and in situ (Gundersen and Jørgensen 1990; Lorke et al. 2003). Glud et al. (2009) document that the vertical distribution of $\mathrm{O}_{2}$ at the SWI of marine sediment can vary temporally (on the order of minutes to hours) by a factor $>3$, which is within the range of seasonal variability for many aquatic systems. Results of these studies highlight the importance of using multiple measurements to resolve average conditions at the SWI. However, isolated measurements evaluating $J_{\mathrm{O}_{2}}$ under conditions assumed constant are sometimes extrapolated to characterize an aquatic system, thereby ignoring the influence of intermittent hydrodynamic processes (Veenstra and Nolen 1991; Beutel 2003).

Despite the established relationship between turbulence and the vertical $\mathrm{O}_{2}$ distribution near the SWI, relatively few studies have incorporated simultaneous measurements of in situ current velocity and $\delta_{\mathrm{DBL}}$ into the assessment of $J_{\mathrm{O}_{2}}$. Previous work has focused predominantly on marine systems (Gundersen and Jørgensen 1990; Glud et al. 2007). Several freshwater experiments were performed to resolve turbulent $\mathrm{O}_{2}$ transport within the BBL (Brand et al. 2008) and the effect of BBL dynamics on $\delta_{\mathrm{DBL}}$ (Lorke et al. 2003); however, these studies primarily characterized turbulence. To our knowledge, no in situ work has been done that focuses on how $J_{\mathrm{O}_{2}}, \delta_{\mathrm{DBL}}$, and the sediment oxic zone vary in response to rapid changes in velocity and direction of basin-scale (i.e., seiche) currents. Additionally, while sediment $\mathrm{O}_{2}$ uptake may be influenced by both hydrodynamics and consumption processes within the sediment (Fig. 1), $J_{\mathrm{O}_{2}}$ is almost always interpreted exclusively from either a water- or sediment-side perspective (Higashino et al. 2004). We performed an in situ study that evaluated data from the water and sediment side of the SWI to determine how seiche-induced turbulence affects $\delta_{\mathrm{DBL}}$, the sediment oxic zone, and corresponding $J_{\mathrm{O}_{2}}$ and $R_{\mathrm{O}_{2}}$ on a rapid (subhourly) timescale. This research is therefore unique in that it assesses the transient nature of sediment $\mathrm{O}_{2}$ uptake by investigating the effect of seiche-induced dynamic forcing on the vertical $\mathrm{O}_{2}$ distribution under natural, in situ conditions from both sides of the SWI.

\section{Methods}

Study site and in situ instrumentation-We performed a 12-h field campaign (21:00 h on 27 August to 09:00 h on 28 August 2007) to obtain high-resolution SWI profile data $\left(\mathrm{O}_{2}\right.$ and temperature $)$ and velocity data in Lake Alpnach, Switzerland. Lake Alpnach has a simple elliptical shape, a well-established deep current structure, and mesotrophic production (Wüest et al. 2000). The lake is characterized by a relatively high $J_{\mathrm{O}_{2}}$ (ranging annually from $\sim 10$ to $\sim 20 \mathrm{mmol} \mathrm{m}^{-2} \mathrm{~d}^{-1}$ ) and a shallow sediment oxic zone $(<3 \mathrm{~mm})$ that establish steep $\mathrm{O}_{2}$ gradients at the SWI (Müller et al. 2002; Lorke et al. 2003). Alpine mountain ridges direct thermal winds over the lake causing basinscale movements of the waterbody. Two seiche modes are typically observed in summer: a first horizontal-first vertical mode with a period of 8 to $12 \mathrm{~h}$ and a first horizontal-second vertical mode with a period of $\sim 24 \mathrm{~h}$ (Münnich et al. 1992; Lorke et al. 2003). The dynamic $\mathrm{O}_{2}$ conditions at the SWI and daily wind forcing make Lake Alpnach an ideal location for this study.

During the campaign, an instrumentation array was deployed on the southwestern slope of Lake Alpnach $\left(46^{\circ} 57^{\prime} 21^{\prime \prime} \mathrm{N}, 8^{\circ} 17^{\prime} 53^{\prime \prime} \mathrm{E}\right)$ at a depth of $22 \mathrm{~m}$. Velocity data were collected continuously at a single point using an acoustic Doppler velocimeter (ADV; Vector, Nortek) and as vertical profiles using an acoustic Doppler profiler (ADP; Aquadopp, Nortek). Thermistors (TR-1060, RBR Ltd.) were placed on the ADP tripod to resolve the temperature structure. A microprofiler (MP4, Unisense A/S) was used to measure highresolution $\mathrm{O}_{2}$ and temperature profiles across the SWI. A conductivity-temperature-depth (CTD; SBE-19, Seabird Electronics) profiler, which also measured $\mathrm{O}_{2}$, was used to profile the water column near the experiment site every $2 \mathrm{~h}$ for background information on $\mathrm{O}_{2}$ and density stratification. Detailed information about the primary components of the experimental setup is provided below. Frequently used acronyms and notations are defined in Table 1.

$A D V$ velocity measurements - $\mathrm{An} \mathrm{ADV}$ was used to continuously measure three-dimensional current time series 
Table 1. Acronyms and notations with corresponding units used for this study.

\begin{tabular}{|c|c|}
\hline ADP & $\begin{array}{l}\text { Acoustic Doppler Aquadopp profiler; used to obtain } \\
\text { velocity profile data }\end{array}$ \\
\hline ADV & $\begin{array}{l}\text { Acoustic Doppler velocimeter; used to obtain local } \\
\text { (pointwise), high-frequency velocity data }\end{array}$ \\
\hline BBL & Bottom boundary layer \\
\hline$D$ & Molecular $\mathrm{O}_{2}$ diffusion coefficient $\left(\mathrm{m}^{2} \mathrm{~d}^{-1}\right)$ \\
\hline DBL & Diffusive boundary layer \\
\hline$C_{\text {bulk }}$ & Concentration of $\mathrm{O}_{2}$ in bulk BBL $(\mu \mathrm{mol} \mathrm{L}-1)$ \\
\hline$C_{\text {SWI }}$ & Concentration of $\mathrm{O}_{2}$ at SWI $(\mu \mathrm{mol} \mathrm{L}-1)$ \\
\hline$\partial C / \partial t_{v}$ & $\begin{array}{l}\text { Volumetric change in } \mathrm{O}_{2} \text { concentration over time } \\
\left(\mathrm{mmol} \mathrm{m}-3 \mathrm{~d}^{-1}\right)\end{array}$ \\
\hline$\partial C / \partial t_{a}$ & $\begin{array}{l}\text { Areal change in } \mathrm{O}_{2} \text { concentration over time } \\
\quad\left(\mathrm{mmol} \mathrm{m} \mathrm{m}^{-2} \mathrm{~d}^{-1}\right)\end{array}$ \\
\hline$\partial C / \partial z$ & $\mathrm{O}_{2}$ concentration gradient $\left(\mathrm{mmol} \mathrm{m}^{-4}\right)$ \\
\hline & SWI flux of $\mathrm{O}_{2}$ into the sediment $\left(\mathrm{mmol} \mathrm{m}-2 \mathrm{~d}^{-1}\right)$ \\
\hline$M_{\mathrm{O}_{2}}$ & $\begin{array}{l}\text { Vertically integrated mass of } \mathrm{O}_{2} \text { in sediment } \\
(\mu \mathrm{mol} \mathrm{m}-2)\end{array}$ \\
\hline $\mathrm{O}_{2}$ & Dissolved oxygen $(\mu \mathrm{mol} \mathrm{L}-1)$ \\
\hline PSOD & Potential sediment $\mathrm{O}_{2}$ demand $\left(\mathrm{mmol} \mathrm{m}-3 \mathrm{~d}^{-1}\right)$ \\
\hline$R_{\mathrm{O}_{2}}$ & $\begin{array}{l}\mathrm{O}_{2} \text { consumption rate in sediment, defined } \\
\text { volumetrically }\left(R_{\mathrm{O}_{2} v}\right) \text { or areally }\left(R_{\mathrm{O}_{2} a}\right)\end{array}$ \\
\hline$R_{\mathrm{O}_{2} a}$ & $\begin{array}{l}\text { Areal } \mathrm{O}_{2} \text { consumption rate in sediment } \\
\quad\left(\mathrm{mmol} \mathrm{m}-2 \mathrm{~d}^{-1}\right) \text { where } R_{\mathrm{O}_{2} a} \text { is the vertical integral } \\
\left.\quad \text { of volumetric } R_{\mathrm{O}_{2} v} \text { (Eq. } 2\right)\end{array}$ \\
\hline$R_{\mathrm{O}_{2} v}$ & $\begin{array}{l}\text { Volumetric } \mathrm{O}_{2} \text { consumption rate in sediment } \\
\quad\left(\mathrm{mmol} \mathrm{m} \mathrm{m}^{-3} \mathrm{~d}^{-1}\right)\end{array}$ \\
\hline SWI & Sediment-water interface \\
\hline$u *$ & Friction velocity $\left(\mathrm{cm} \mathrm{s}^{-1}\right)$ \\
\hline$z$ & Distance above or below SWI (mm) \\
\hline$z_{\max }$ & Depth of sediment oxic zone (mm) \\
\hline$\delta_{\mathrm{DBL}}$ & DBL thickness (mm) \\
\hline$\varepsilon$ & Dissipation rate of turbulent kinetic energy $\left(\mathrm{W} \mathrm{kg}^{-1}\right)$ \\
\hline$\varphi$ & $\begin{array}{l}\text { Porosity (void volume per total sediment volume; } \\
\text { dimensionless) }\end{array}$ \\
\hline$\sigma$ & $\begin{array}{l}\text { Standard deviation (units correspond to parameter } \\
\text { of interest) }\end{array}$ \\
\hline
\end{tabular}

at $32 \mathrm{~Hz}$, positioned via tripod at $10 \mathrm{~cm}$ above the SWI. Accuracy of the velocity measurements is $0.5 \%$ of measured value $\pm 0.1 \mathrm{~cm} \mathrm{~s}^{-1}$. ADV velocity data were used to analyze the current structure and to estimate energy dissipation rate and friction velocity at $10 \mathrm{~cm}$ above the SWI.

ADP velocity measurements-A 2-MHz ADP equipped with three acoustic beams slanted at $25^{\circ}$ was used to measure BBL current profiles. Accuracy of the velocity measurements is $1 \%$ of measured value $\pm 0.5 \mathrm{~cm} \mathrm{~s}^{-1}$. The ADP was positioned (via tripod) downward looking and measured profiles from $1.60 \mathrm{~m}$ to $0 \mathrm{~m}$ above the sediment, with 32 measurement cells $(5-\mathrm{cm}$ bin size). Samples were obtained in burst mode with 1024 samples per ensemble at a rate of $8 \mathrm{~Hz}$. ADP velocity data were used to estimate bottom drag coefficients at $1 \mathrm{~m}$ above the SWI as an independent verification of ADV velocity data.

$\mathrm{O}_{2}$ and temperature logger measurements-BBL temperature (i.e., density) structure was continuously measured using a string of 20 thermistors positioned every $25 \mathrm{~cm}$ on the leg of the ADP tripod, from $0 \mathrm{~m}$ to $4.75 \mathrm{~m}$ above the sediment. Measurements were obtained using TR-1060 thermistors, which have a response time of $<3 \mathrm{~s}$, accuracy of $\pm 2 \times 10^{-3}{ }^{\circ} \mathrm{C}$, resolution of $<5 \times 10^{-5}{ }^{\circ} \mathrm{C}$, and drift of $<2 \times 10^{-3}{ }^{\circ} \mathrm{C} \mathrm{yr}^{-1}$. A logger measuring both temperature and $\mathrm{O}_{2}$ (TDO-2050, RBR Ltd.) was mounted on the microprofiler at $8 \mathrm{~cm}$ above the sediment. In addition to TR-1060 temperature specifications, the TDO-2050 has a measurement range of $0 \%$ to $150 \% \mathrm{O}_{2}$ saturation, with an accuracy of $\pm 1 \%$. TDO- $2050 \mathrm{O}_{2}$ data were calibrated via Winkler titration of BBL water sampled at the same depth using a Niskin bottle. The calibrated TDO time series and a zero reading from anoxic sediment were then used for calibration of microprofiler $\mathrm{O}_{2}$ measurements.

Microsensor $\mathrm{O}_{2}$ and temperature measurements across $S W I$-An in situ autonomous microprofiler equipped with microsensors (one Clark-type $\mathrm{O}_{2}$ sensor and one thermocoupled temperature sensor, Unisense A/S) was used for microprofiling across the SWI. The sensors have tip diameters of $100 \mu \mathrm{m}$, which allow for fast response time $(90 \%$ in $<8 \mathrm{~s}$ ), negligible stirring sensitivity, and $\sim 100-\mu \mathrm{m}$ spatial resolution. Vertical alignment of the microsensors was established by lowering the group of microsensors toward quiescent water and adjusting sensors until all tips touched the water surface simultaneously. Profiles were obtained every $\sim 50 \mathrm{~min}$ and were acquired as follows: $10-\mathrm{mm}$ resolution from $10 \mathrm{~cm}$ to $1 \mathrm{~cm}$ above the SWI, 1-mm resolution from $1 \mathrm{~cm}$ to $0.5 \mathrm{~cm}$ above the SWI, 0.1-mm resolution from $0.5 \mathrm{~cm}$ above to $0.5 \mathrm{~cm}$ below the SWI. Following a brief pause to establish equilibrium, ten data points were collected at each depth at a rate of $1 \mathrm{~Hz}$ (inspection of measurement set showed no trend in variation, thus confirming data aliasing did not occur).

We measured $14 \mathrm{O}_{2}$ profiles during the experiment. The $\mathrm{O}_{2}$ profile number $(1-14)$ corresponds to the time each profile was obtained and is used as a reference for comparison with other parameters (e.g., turbulence). In the absence of a video camera, the location of the SWI was determined by both visual interpretation of each profile (based on identifying linear DBL regions and kinks in the profiles due to porosity differences between the sediment and the water column; Røy et al. 2004) and using standard deviations of $\mathrm{O}_{2}$ profile data (variation should decrease approaching the SWI due to reduced fluctuations in turbulence; Müller et al. 2002; Brand et al. 2007). Estimates of the SWI using $\mathrm{O}_{2}$ standard deviations were comparable to estimates based on visual interpretation, though consistently $\sim 1 \mathrm{~mm}$ deeper. Correspondingly, previous work has shown the variance method to systematically overestimate $\delta_{\mathrm{DBL}}$ due to concentration fluctuations protruding into the sediment (Røy et al. 2004). The SWI location predicted by both methods did remain relatively constant across our profile series, however. Hence, even if the estimated SWI location was slightly erroneous, this would not affect comparison among profiles.

$\mathrm{O}_{2}$ uptake and DBL analyses- $\mathrm{O}_{2}$ uptake is frequently evaluated for cohesive sediment using a water-side approach based on Fick's first law of diffusion (Rasmussen 
and Jørgensen 1992)

$J_{\mathrm{O}_{2}}=\varphi D \frac{\partial C}{\partial z}=\varphi D \frac{C_{\text {bulk }}-C_{\mathrm{SWI}}}{\delta_{\mathrm{DBL}}}\left[\mathrm{mmol} \mathrm{m}^{-2} \mathrm{~d}^{-1}\right]$

where $D$ is the molecular diffusion coefficient for $\mathrm{O}_{2}$ in water $\left(\mathrm{m}^{2} \mathrm{~d}^{-1}\right), \varphi$ is porosity $\left(\mathrm{m}^{3}\right.$ voids $\mathrm{m}^{-3}$ total volume; taken as unity in the water column), and $\partial C / \partial z$ is the linear $\mathrm{O}_{2}$ concentration gradient in the DBL immediately above the SWI (i.e., the change in the $\mathrm{O}_{2}$ concentration, $C$, over distance $\left.z ; \mathrm{mmol} \mathrm{m}^{-4}\right)$.

While this is one of the most direct approaches for evaluating $J_{\mathrm{O}_{2}}$, there are several problems associated with quantifying $\delta_{\mathrm{DBL}}$. The short residence time of $\mathrm{O}_{2}$ near the SWI and rapid variations in $\delta_{\mathrm{DBL}}$ due to $\mathrm{BBL}$ turbulence make it difficult to accurately characterize the DBL with microsensor measurements (Røy et al. 2004; O'Connor and Hondzo 2008). Furthermore, the transition from the linear DBL to the bulk BBL region is often indistinct (Wüest and Lorke 2003). To address this issue, Jørgensen and Revsbech (1985) established an "effective" DBL, obtained by extrapolating $\partial C / \partial z$ at the SWI to the point where $\mathrm{O}_{2}$ levels reach the average concentration of the BBL $\left(C_{\text {bulk }}\right.$; Fig. 1) as defined by the second part of Eq. 1 (on the righthand side). It has been shown, however, that $\delta_{\mathrm{DBL}}$ is often overestimated by the effective DBL (Hondzo et al. 2005; O'Connor and Hondzo 2008). Additionally, microsensors have been found to alter the structure of the DBL by $~ 25$ $45 \%$, possibly due to increased flow around the microsensor shaft compressing the DBL below the sensor tip (Glud et al. 1994; Glud 2008). A decreased $\delta_{\text {DBL }}$ caused by microsensor compression would obviously result in an overestimation of $J_{\mathrm{O}_{2}}$. Considering the variability of the DBL and subsequent difficulties in characterizing $\delta_{\mathrm{DBL}}$, it may be more appropriate to regard $\delta_{\mathrm{DBL}}$ as a conceptual parameter rather than as a physical quantity.

Although problems with quantifying $\delta_{\mathrm{DBL}}$ are avoided when using sediment-side methods, these methods are often more intensive due to relatively complex sediment processes. In addition to accounting for $\varphi$ effects (Eq. 1), changes in $\mathrm{O}_{2}$ consumption and storage in the sediment must also be accurately quantified. The balance between the amount of $\mathrm{O}_{2}$ taken up by the sediment (characterized by $J_{\mathrm{O}_{2}}$ ) and the amount consumed within the sediment (characterized by $R_{\mathrm{O}_{2}}$ ) is shown by

$$
J_{\mathrm{O}_{2}}=\int_{0}^{z_{\max }} R_{\mathrm{O}_{2} v} d z+\int_{0}^{z_{\max }} \frac{\partial C}{\partial t_{v}} d z\left[\mathrm{mmol} \mathrm{m}^{-2} \mathrm{~d}^{-1}\right]
$$

where volumetric $R_{\mathrm{O}_{2} v}\left(\mathrm{mmol} \mathrm{m}^{-3} \mathrm{~d}^{-1}\right)$ and the change in $\mathrm{O}_{2}$ concentration over time $\left(\partial C / \partial t_{v} ; \mathrm{mmol} \mathrm{m} \mathrm{m}^{-3} \mathrm{~d}^{-1}\right)$ are integrated over the sediment profile to $z_{\max }$ (designated in this study as the depth where $\mathrm{O}_{2}<3 \mu \mathrm{mol} \mathrm{L}-1$ ). The first term on the right-hand side of Eq. 2 represents the amount of $\mathrm{O}_{2}$ consumed per unit of time, while the second term represents the temporal change of the $\mathrm{O}_{2}$ content in the sediment (Higashino et al. 2004). Depth-integrated values from Eq. 2 are defined by areal $R_{\mathrm{O}_{2} a}$ and $\partial C / \partial t_{a}$, respectively $\left(\mathrm{mmol} \mathrm{m}{ }^{-2} \mathrm{~d}^{-1}\right.$; Table 1), for each profile to allow for direct comparison with $J_{\mathrm{O}_{2}}$. Equation 2 shows that $J_{\mathrm{O}_{2}}$ and $R_{\mathrm{O}_{2} a}$ are equal at steady state, whereas $\mathrm{O}_{2}$ accumulation or depletion $\left(\partial C / \partial t_{a}\right)$ occurs during transient conditions.

To comprehensively assess how dynamic forcing affects sediment $\mathrm{O}_{2}$ uptake, we analyzed $J_{\mathrm{O}_{2}}$ and $\delta_{\text {DBL }}$ for each $\mathrm{O}_{2}$ microsensor profile with five different methods that incorporated data from both the water side (direct and $u_{*}$ methods) and sediment side (curvefit, zonefit, and model methods) of the SWI. These five methods were selected to evaluate $J_{\mathrm{O}_{2}}$ using $\mathrm{O}_{2}$ microsensor and velocity data. Problems with specific measurement techniques (e.g., measuring $\delta_{\mathrm{DBL}}$ ) or analytical methods should be minimized by the use of a combination of methods based on water-side velocities and water- and sediment-side microsensor data. A more detailed comparison of the methods used to estimate sediment $\mathrm{O}_{2}$ uptake will be presented in a companion paper (L. Bryant unpubl. data).

For the direct method, $\partial C / \partial z$ was obtained directly from the DBL region of $\mathrm{O}_{2}$ microsensor profiles and then incorporated into Eq. 1 to evaluate $\delta_{\mathrm{DBL}}$ and $J_{\mathrm{O}_{2}}$ (Jørgensen and Revsbech 1985). For the $u_{*}$ method (Hondzo et al. 2005), dimensionless power law scaling was applied to friction velocity $(u *)$ data derived from ADV velocity series to universally scale the vertical $\mathrm{O}_{2}$ distribution in the $\mathrm{BBL}$ for $\delta_{\mathrm{DBL}}$, which was then used to solve for $J_{\mathrm{O}_{2}}$ via Eq. 1 .

$\mathrm{O}_{2}$ profile data from the sediment side were evaluated by fitting a polynomial equation $C(z)$ to the porewater region of each $\mathrm{O}_{2}$ profile, focusing on the region immediately below the SWI (curvefit method). The derivative of $C(z)$ was then incorporated into Eq. 1 to solve for $J_{\mathrm{O}_{2}}$ and $\delta_{\mathrm{DBL}}$ (Glud 2008). Third-order $C(z)$ polynomial equations were found to best fit the series of profile data, with the exception of profile 6 , which required a fourth-order polynomial.

Porewater data were also evaluated using the numerical model PROFILE (Berg et al. 1998), which analyzes data based on a numerical analysis that defines multiple zones of constant consumption to best describe each $\mathrm{O}_{2}$ profile (zonefit method). Integrating depth-specific $R_{\mathrm{O}_{2} v}$ (evaluated at $0.1-\mathrm{mm}$ increments) over the depth of the sediment oxic zone yields the overall areal $R_{\mathrm{O}_{2} a}$ per profile. $R_{\mathrm{O}_{2} a}$ can then be used to calculate $J_{\mathrm{O}_{2}}$ via Eq. 2. Model parameters used include $D=1.97 \times 10^{-9} \mathrm{~m}^{2} \mathrm{~s}^{-1}$ at $20^{\circ} \mathrm{C}$ (corrected for temperature using the Stokes-Einstein relationship; Li and Gregory 1974; Agrega and Lee 2005), with irrigation and bioturbation effects assumed negligible and boundary conditions (evaluated at the bottom of each profile) of $J_{\mathrm{O}_{2}}=0 \mathrm{mmol} \mathrm{m}{ }^{-2} \mathrm{~d}^{-1}$ and $C=0 \mu \mathrm{mol} \mathrm{L}^{-1}$.

We further analyzed sediment porewater data with the sediment module of the aquatic system simulation software AQUASIM (Reichert 1994), which was used to predict the $\delta_{\text {DBL }}$ required to model $\mathrm{O}_{2}$ porewater profiles via a simple Monod model for $\mathrm{O}_{2}$ consumption (model method). Model parameters and setup details for the AQUASIM model used in this study are defined by Brand et al. (2009). We were able to accurately model our series of sediment $\mathrm{O}_{2}$ profiles in AQUASIM with a single set of Monod parameters (maximum oxidation rate $(\mu)=5920 \mathrm{mmol}$ $\mathrm{m}^{-3} \mathrm{~d}^{-1}$ and half-saturation constant $\left(K_{\mathrm{O}_{2}}\right)=19.1 \mu \mathrm{mol}$ $\mathrm{L}^{-1}$ ) and $C_{\mathrm{SWI}}$ as the only variable. We then incorporated these Monod parameters into a second model (see Eq. 6 in Brand et al. 2009) in which $C_{\text {bulk }}$ was designated as the 
upper boundary condition and $\delta_{\mathrm{DBL}}$ was used as the sole fitting parameter to reproduce our sediment $\mathrm{O}_{2}$ profiles.

Sediment cores from our experiment site were analyzed for $\varphi$ (porewater volume per total volume) following Dalsgaard et al. (2000) to characterize diffusive transport in the sediment, and $\varphi$ values of 0.97 and 0.91 in the upper $5 \mathrm{~mm}$ were obtained. Using these $\varphi$ results as a point of reference and $J_{\mathrm{O}_{2}}$ values from an independent set of profiles (obtained $\sim 1 \mathrm{~m}$ from our experiment site, measured prior to the series of 14 assessed in the primary study) as goals, $\varphi$ was also estimated on a millimeter scale with PROFILE (which uses $\varphi$ as an input parameter) via a trial-and-error approach. Similar porosities $(0.95$ in the upper $1 \mathrm{~mm}$ of sediment and 0.90 below) were obtained, and these $\varphi$ values were used in Eq. 1 and/or as model parameters.

The transience of our system and sediment $\mathrm{O}_{2}$ consumption as a function of $\mathrm{O}_{2}$ availability were evaluated using Eq. 2. Proximity to steady state was determined by calculating $\partial C / \partial t_{a}$ for each profile by comparing the preceding and following profiles, evaluating $\partial C / \partial t_{v}$ at each depth, and integrating over $z_{\max }$. Because the direct, $u_{*}$, curvefit, and model methods estimate $J_{\mathrm{O}_{2}}$ directly, results from these methods were used to evaluate $\mathrm{O}_{2}$ consumption (as characterized by $R_{\mathrm{O}_{2} a}$ ) via Eq. 2 as a function of $\partial C / \partial t_{a}$. The zonefit method predicts depth-specific $\mathrm{O}_{2}$ consumption directly, and hence Eq. 2 was used to estimate $J_{\mathrm{O}_{2}}$ from $R_{\mathrm{O}_{2} a}$ values based on PROFILE results.

Using results of the five methods, mean values of $J_{\mathrm{O}_{2}}$, $R_{\mathrm{O}_{2} a}$, and $\delta_{\mathrm{DBL}}$ were calculated for each profile. These parameters were statistically analyzed based on a normal distribution. Standard deviations $(\sigma)$ were calculated for $J_{\mathrm{O}_{2}}$ and $\delta_{\mathrm{DBL}}$ data ( $\sigma$ calculations for $R_{\mathrm{O}_{2} a}$ were unnecessary since $J_{\mathrm{O}_{2}}$ and $R_{\mathrm{O}_{2} a}$ are directly correlated via Eq. 2 ). Estimates obtained from the five methods were comparable, as shown below.

Inertial dissipation analyses-The dissipation rate of turbulent kinetic energy, $\varepsilon\left(\mathrm{W} \mathrm{kg}^{-1}\right)$, was estimated using the inertial dissipation method (Grant et al. 1962). The analysis is based on the inertial subrange where the spectrum is expressed in the wave number $(k)$ domain

$$
E(k)=\alpha \varepsilon^{2 / 3} k^{-5 / 3}\left[\mathrm{~m}^{3} \mathrm{~s}^{-2}\right]
$$

where velocity fluctuation follows a $k^{-5 / 3}$ slope for eddy sizes of typically decimeters to meters (Fig. 2a). We used $\alpha$ $=1.56$ for the experimentally estimated, three-dimensional Kolmogorov constant (Wyngaard and Coté 1971). With the ADV, we measured horizontal (longitudinal and lateral) and vertical velocity fluctuations $10 \mathrm{~cm}$ above the sediment. Dissipation rates can be obtained from the longitudinal component of the one-dimensional spectrum expressed in the wave number $\left(k_{1}\right)$ domain

$$
\varphi_{11}\left(k_{1}\right)=\alpha_{1} \varepsilon^{2 / 3} k_{1}^{-5 / 3}\left[\mathrm{~m}^{3} \mathrm{~s}^{-2}\right]
$$

and the two transversal components of the power spectrum

$$
\varphi_{22}\left(k_{1}\right)=\varphi_{33}\left(k_{1}\right)=\alpha_{2} \varepsilon^{2 / 3} k_{1}{ }^{-5 / 3}\left[\mathrm{~m}^{3} \mathrm{~s}^{-2}\right]
$$

where $\alpha_{1}=(18 / 55) \alpha$ and $\alpha_{2}=(4 / 3) \alpha_{1}$. Rather than fitting the $-5 / 3$ slope to the inertial subrange, the respective power spectrum (Eqs. 4 and 5) is multiplied by $k^{5 / 3}$. This procedure transforms the spectrum so that it is only dependent on $\varepsilon$ as $E(k) \times k^{5 / 3}$ becomes constant (Fig. 2a). Dissipation $(\varepsilon)$ is then calculated by taking the average of the inertial subrange. All three velocity fluctuation records were used to quantify the value of $\varepsilon$ (longitudinal, transversal planar, and transversal vertical; Eqs. 4 and 5) over a time span of approximately 50 min (Fig. 2b), which corresponds to the measurement period of each $\mathrm{O}_{2}$ profile.

To account for the intermittency of turbulence, $\varepsilon$ is averaged by assuming a lognormal distribution (Baker and Gibson 1987). The most likely average of the three $\varepsilon$ values $(\bar{\varepsilon})$ is

$$
\bar{\varepsilon}=\exp \left(\overline{\ln (\varepsilon)}+\frac{\sigma_{\ln (\varepsilon)}^{2}}{2}\right)\left[\mathrm{W} \mathrm{kg}^{-1}\right]
$$

where $\overline{\ln (\varepsilon)}$ is the average of the $\ln$ value of $\varepsilon$ and $\sigma_{\ln (\varepsilon)}$ is the standard deviation, or intermittency, of the $\ln (\varepsilon)$ values (Table 2).

Friction velocity analyses-Friction velocities $\left(u_{*}\right)$ were calculated at a height $(h)$ of $10 \mathrm{~cm}$ above the sediment from the estimated $\varepsilon$ values using the law-of-the-wall assumption

$$
u_{*}=\sqrt[3]{\varepsilon \kappa h}\left[\mathrm{~m} \mathrm{~s}^{-1}\right]
$$

where $\kappa$ (the von Karman constant) is 0.41 . The resulting $u_{*}$ values (Table 2) quantify the frictional stress of BBL currents on the sediment and, thus, like $\varepsilon$, describe the level of turbulence in the BBL.

\section{Results}

Seiche dynamics-We acquired data for $12 \mathrm{~h}$ and captured a full 8-h seiche cycle. During the campaign, bottom currents moved initially from the southwest toward the northeast, reached the current reversal point, and then reversed direction toward the southwest, similar to the motion of a pendulum (as depicted in Fig. 3a, where the schematics show the waterbody moving back and forth relative to our experiment site). Corresponding changes in current velocity are shown in Fig. 3b. During the observed seiche cycle, water from higher elevations in the BBL moved down the southwestern slope with increasing velocity toward the northeast. Current velocity reached a maximum of $2.3 \mathrm{~cm} \mathrm{~s}^{-1}$ (at 23:50 h) during this period. At the current reversal point $(\sim 04: 00 \mathrm{~h})$, velocities in the BBL reached a minimum value of $0.6 \mathrm{~cm} \mathrm{~s}^{-1}$. When the water mass then shifted back toward the southwest, water from the central region of the BBL moved toward the southwestern slope and velocities increased to levels observed prior to current reversal, reaching a maximum value of $2.3 \mathrm{~cm} \mathrm{~s}^{-1}$ (at $07: 44 \mathrm{~h}$ ).

Lorke et al. (2002) demonstrated that law-of-the-wall theory (used to estimate $u_{*}$ ) only applies in cases of turbulence where longitudinal velocity is greater than $1 \mathrm{~cm} \mathrm{~s}^{-1}$ at $1 \mathrm{~m}$ above the sediment. Most of our velocities (obtained at $10 \mathrm{~cm}$ above the sediment) were within this 

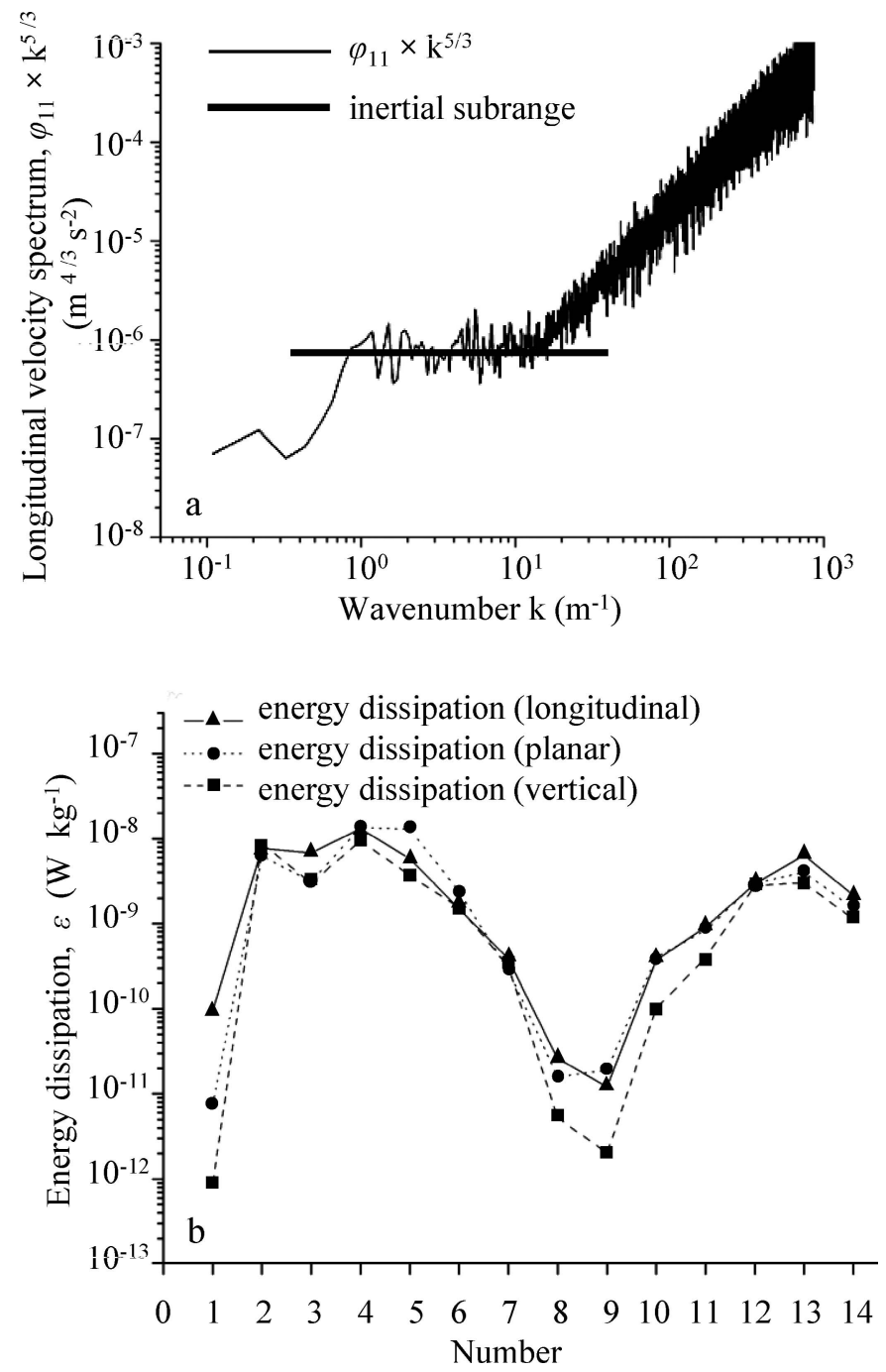

Fig. 2. (a) The measured longitudinal velocity spectrum $\varphi_{11}$ (with $k^{-5 / 3}$ slope characteristic in the inertial subrange) is multiplied by $k^{5 / 3}$ to be independent of wave number $k$. The constant value of $\varphi_{11} \times k^{5 / 3}$, indicated by the horizontal bar, is used to calculate the mean energy dissipation $(\varepsilon)$. (b) Dissipation rates $(\varepsilon)$ calculated by inertial dissipation method using longitudinal, planar, and vertical velocity data as measured via acoustic Doppler velocimeter (ADV). Note similarity in longitudinal and transversal $\varepsilon$ values.

range, with only velocities during the period of current reversal (profiles 7-9) falling significantly below this level (Fig. 3b). Accordingly, a majority of our profiles were consistent with the law-of-the-wall profile. However, for velocities smaller than this threshold, the logarithmic profile broke down and no characteristic features of the BBL could be identified (as independently confirmed by $\mathrm{O}_{2}$ microsensor measurements). To verify the applicability of the law-of-the-wall to the full series of our velocity data, we employed the bottom drag coefficient $\left(C_{1 \mathrm{~m}}\right)$ via

$$
u_{*}=\sqrt{C_{1 \mathrm{~m}}} U_{1 \mathrm{~m}}\left[\mathrm{~m} \mathrm{~s}^{-1}\right]
$$

where $U_{1 \mathrm{~m}}$ is the longitudinal velocity $\left(\mathrm{m} \mathrm{s}^{-1}\right)$ at $1 \mathrm{~m}$ above the sediment obtained from the downward-looking ADP.
The bottom drag coefficient relates the Reynolds stress on the sediment surface and the mean current velocity at a specified height. A $C_{1 \mathrm{~m}}$ value of 0.0033 was obtained for the full set of velocity data and a $C_{1 \mathrm{~m}}$ of 0.0013 was obtained when the velocity data below $1 \mathrm{~cm} \mathrm{~s}^{-1}$ were excluded. These $C_{1 \mathrm{~m}}$ values are comparable to the typical range of 0.001-0.003 (Wüest and Lorke 2003) for smoothbottom boundaries (such as lake bottom sediments).

Temperature and $\mathrm{O}_{2}$ distribution-Temperature and $\mathrm{O}_{2}$ in the water column and near the sediment are shown to be strongly affected by seiche-induced variations in current velocity (Figs. 3, 4). At the beginning of the measurement period $(21: 00 \mathrm{~h})$, a cold water mass from the central, wellmixed BBL moved across the experiment site (Fig. $4 \mathrm{a}-\mathrm{c}$ ). As the water mass shifted toward the northeast, warmer water from the upper BBL moved toward the experiment site (approaching 04:00 h) as the current reversal point was approached (Fig. 3). Following reversal of current direction, velocity increased and the cooler, well-mixed region of the BBL moved back to the experiment site as the current shifted the water mass toward the southwest.

Variations in temperature and $\mathrm{O}_{2}$ in the $\mathrm{BBL}$ at $8 \mathrm{~cm}$ above the sediment are shown in Fig. 4a. Changes in temperature are shown as a function of depth in Fig. $4 \mathrm{~b}$ (200 to $30 \mathrm{~cm}$ above the SWI) and Fig. $4 \mathrm{c}(1 \mathrm{~cm}$ above to $0.25 \mathrm{~cm}$ below the SWI). From Fig. 4b,c, it is apparent that while temperature varied over time (on the order of $\sim 2^{\circ} \mathrm{C}$ ), the vertical temperature profile remained relatively constant with depth but was displaced first in the positive and then negative direction. However, while changes in $\mathrm{O}_{2}$ are relatively minor (on the order of $\sim 10 \mu \mathrm{mol} \mathrm{L}^{-1}$ ) at $8 \mathrm{~cm}$ above the sediment (Fig. 4a), $\mathrm{O}_{2}$ variations are observed on a much greater scale near the SWI (Fig. $4 \mathrm{~d} ; 1 \mathrm{~cm}$ above to $0.25 \mathrm{~cm}$ below the SWI). When velocity decreased during profiles 5 to $9, \mathrm{O}_{2}$ decreased from $\sim 100 \mu \mathrm{mol} \mathrm{L}^{-1}$ to $70 \mu \mathrm{mol} \mathrm{L}{ }^{-1}$ at $1 \mathrm{~cm}$ above the SWI and from $59 \mu \mathrm{mol} \mathrm{L}-1$ to $5 \mu \mathrm{mol} \mathrm{L} ~^{-1}$ at the SWI. Furthermore, the sediment approached anoxia as sediment $\mathrm{O}_{2}$ was depleted during this period.

The controlling influence that dynamic forcing has on the vertical distribution of $\mathrm{O}_{2}$ above and below the SWI is emphasized in Fig. 5. $\mathrm{O}_{2}$ profiles are separated into panels according to the direction of profile movement, which strongly corresponds to changes in velocity magnitude. The oscillating motion of the waterbody is apparent in the directional shifts of the $\mathrm{O}_{2}$ profiles over the seiche cycle. As currents intensify, $\mathrm{O}_{2}$ levels in the water and in the sediment increase, as shown by profiles 2-5 (Fig. 5a) and 9-14 (Fig. 5c); however, as velocity decreases approaching current reversal, $\mathrm{O}_{2}$ throughout the full length of the profile drops to negligible levels (profiles 5-9; Fig. 5b). Profile 1 is not shown due to a slight misalignment with the other profiles that likely resulted from equipment settling into the sediment following deployment (discussed further below). A key point shown in Fig. 5 is the elasticity of the system, in that the vertical $\mathrm{O}_{2}$ distribution changes significantly as it shifts from oxic (Fig. 5a) to nearly anoxic conditions (Fig. 5b), but then it returns to an oxic distribution (Fig. 5c) as it was in its initial state (Fig. 5a). 
Table 2. Mean estimates of friction velocity $\left(u_{*}\right)$, energy dissipation rate $(\varepsilon)$, and intermittency $\left(\sigma_{\ln (\varepsilon)}\right)$ of $\varepsilon$.

\begin{tabular}{|c|c|c|c|c|}
\hline Profile number* & Time sensors contacted SWI* & Friction velocity, $u_{*}\left(\mathrm{~cm} \mathrm{~s}^{-1}\right)$ & $\begin{array}{l}\text { Energy dissipation } \\
\text { rate, } \varepsilon\left(\mathrm{W} \mathrm{kg}^{-1}\right)\end{array}$ & $\begin{array}{c}\varepsilon \text { intermittency, } \\
\sigma_{\ln (\varepsilon)}(-)\end{array}$ \\
\hline $1 \dagger$ & 27 August 2007 21:14 h & $(0.007)$ & $\left(8.4 \times 10^{-12}\right)$ & $(2.4)$ \\
\hline 2 & $22: 05 \mathrm{~h}$ & 0.067 & $7.5 \times 10^{-9}$ & 0.2 \\
\hline 3 & $22: 57 \mathrm{~h}$ & 0.055 & $4.0 \times 10^{-9}$ & 0.5 \\
\hline 4 & $23: 50 \mathrm{~h}$ & 0.079 & $1.2 \times 10^{-8}$ & 0.2 \\
\hline 5 & 28 August 2007 00:42 h & 0.064 & $6.5 \times 10^{-9}$ & 0.6 \\
\hline 6 & $01: 36 \mathrm{~h}$ & 0.042 & $1.8 \times 10^{-9}$ & 0.3 \\
\hline 7 & $02: 27 \mathrm{~h}$ & 0.024 & $3.2 \times 10^{-10}$ & 0.2 \\
\hline 8 & $03: 19 \mathrm{~h}$ & 0.008 & $1.3 \times 10^{-11}$ & 0.8 \\
\hline 9 & $04: 12 \mathrm{~h}$ & 0.007 & $7.8 \times 10^{-12}$ & 1.2 \\
\hline 10 & $05: 05 \mathrm{~h}$ & 0.022 & $2.5 \times 10^{-10}$ & 0.8 \\
\hline 11 & $05: 59 \mathrm{~h}$ & 0.030 & $6.7 \times 10^{-10}$ & 0.5 \\
\hline 12 & $06: 53 \mathrm{~h}$ & 0.049 & $2.9 \times 10^{-9}$ & 0.0 \\
\hline 13 & $07: 44 \mathrm{~h}$ & 0.056 & $4.2 \times 10^{-9}$ & 0.4 \\
\hline 14 & $08: 37 \mathrm{~h}$ & 0.040 & $1.6 \times 10^{-9}$ & 0.3 \\
\hline
\end{tabular}

* Data are compared by profile number, which represents the time each microsensor profile was obtained during the Alpnach campaign. The time assigned to each profile was the time at which the microsensor encountered the SWI.

$\dagger$ Outlier data for profile 1 placed in parentheses.

In Fig. 5a (profiles 2-5) and Fig. 5c (profiles 9-14), the oxic zone extends further into the sediment and $\delta_{\mathrm{DBL}}$ decreases as velocity increases, clearly illustrating how current-induced mixing forces the vertical $\mathrm{O}_{2}$ structure at the SWI. After velocity peaked at approximately $23: 50 \mathrm{~h}$ (Fig. 5a), $z_{\max }$ and $C_{\text {SWI }}$ reached maximum values $(2.2 \mathrm{~mm}$

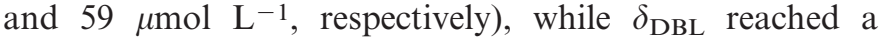
minimum of $1.0 \mathrm{~mm}$. This relationship is shown in reverse in Fig. 5b (profiles 5-9) where, as velocity decreases during current reversal (between profiles 8 and 9 at approximately 04:00 h), $\delta_{\text {DBL }}$ increases to the point of being undefined, and the oxic zone almost completely disappears (minimum $\mathrm{z}_{\max }=0.3 \mathrm{~mm}$ ) as the sediment goes anoxic.

$\mathrm{O}_{2}$ flux and $\delta_{D B L}-$ Mean values of $J_{\mathrm{O}_{2}}$ and $\delta_{\mathrm{DBL}}$ were obtained by averaging results from the five analytical methods used to evaluate $\mathrm{O}_{2}$ profile and $u_{*}$ data (Table 3). Consequently, both water-side (transport) and sedimentside (consumption) influences on $J_{\mathrm{O}_{2}}$ and $\delta_{\mathrm{DBL}}$ are reflected in the average values. Values of $J_{\mathrm{O}_{2}}$ based on $R_{\mathrm{O}_{2} a}$ from the zonefit model were corrected for transient accumulation of $\mathrm{O}_{2}$ per Eq. 2. During energetic periods (maximum $\varepsilon=1.2$ $\times 10^{-8} \mathrm{~W} \mathrm{~kg}^{-1}$; profile 4$), \delta_{\text {DBL }}$ reached a minimum of $1.0 \mathrm{~mm}$ and $J_{\mathrm{O}_{2}}$ increased to a maximum of $7.0 \mathrm{mmol} \mathrm{m} \mathrm{m}^{-2} \mathrm{~d}^{-1}$ (Table 3). As turbulence decreased approaching the current reversal point (minimum $\varepsilon=7.8 \times$ $10^{-12} \mathrm{~W} \mathrm{~kg}^{-1}$; profile 9), $\delta_{\mathrm{DBL}}$ expanded significantly, since there was no longer sufficient turbulence to maintain an established DBL (Fig. 5; Table 3). Although a DBL in the classical sense is not maintained under these quiescent conditions (Gantzer and Stefan 2003; Røy et al. 2004), we nevertheless quantified $\delta_{\mathrm{DBL}}$ during this period as a relative measure for comparison. Using independent results from all five methods, a maximum average $\delta_{\mathrm{DBL}}$ of $7.8 \pm 2.2 \mathrm{~mm}$ was estimated for profile 9 (Table 3 ).

During the period of weak turbulence and subsequently increased $\delta_{\mathrm{DBL}}, J_{\mathrm{O}_{2}}$ decreased by $85 \%$, from $7.0 \mathrm{mmol} \mathrm{m}^{-2} \mathrm{~d}^{-1}$ to $1.1 \mathrm{mmol} \mathrm{m}^{-2} \mathrm{~d}^{-1}$ (Fig. 6). The substantial short-term variability in $J_{\mathrm{O}_{2}}$ in response to changes in turbulence is emphasized in Fig. 6. However, an explicit relationship between $J_{\mathrm{O}_{2}}$ and $\varepsilon$ cannot be defined by the linear correlation shown in Fig. 6, since $J_{\mathrm{O}_{2}}$ is also affected by other variables (e.g., $C_{\text {bulk }}$ and $R_{\mathrm{O}_{2}}$ ).

The relatively small standard deviation of $J_{\mathrm{O}_{2}}$ and $\delta_{\mathrm{DBL}}$ obtained from the different methods per profile as compared to the overall temporal variation in averages $\left(J_{\mathrm{O}_{2}}\right.$ or $\left.\delta_{\mathrm{DBL}}\right)$ shows that similar estimates were obtained from the different methods (Table 3). Water-side methods did tend to yield somewhat higher values of $J_{\mathrm{O}_{2}}$ (with correspondingly lower values of $\delta_{\mathrm{DBL}}$ ). A comparative evaluation of method results is being performed for the companion methods study (L. Bryant, unpubl. data). Standard deviation evolves according to changes in turbulence. When turbulence levels are low, increasing $\delta_{\text {DBL }}$ and decreasing $\varepsilon$ lead to greater uncertainty and subsequently higher $\sigma$ (or intermittency) for these parameters. Thus, observed increases in variability in $\delta_{\mathrm{DBL}}$ and $\varepsilon$ during the period of weak turbulence (Tables 2 and 3 ) are more an effect of analysis than a reflection of the quality of data. While $J_{\mathrm{O}_{2}}, \delta_{\mathrm{DBL}}$, and $\varepsilon$ values for profile 1 exhibit unusually high variability, these increased deviations are reflected in data obtained with multiple instruments (ADV and microprofiler; Tables 2 and 3 ) and are observed only at the beginning of the campaign; hence, they are likely a result of equipment settling at the lake bottom following deployment.

Sediment oxic zone-Changes in the extent of the sediment oxic zone correspond to variations in $J_{\mathrm{O}_{2}}$ and $\delta_{\text {DBL }}$ in response to turbulence. When $\mathrm{O}_{2}$ transport into the sediment escalated as the DBL was compressed by elevated turbulence (Fig. 6), both $z_{\max }$ (Fig. 5) and the vertically integrated mass of $\mathrm{O}_{2}\left(M_{\mathrm{O}_{2}}\right.$; Table 4) increased significantly as $\mathrm{O}_{2}$ penetrated deeper into the sediment. The oxic zone is observed to reach a maximum $z_{\max }$ of $2.2 \mathrm{~mm}$ during active turbulence (corresponding $\delta_{\mathrm{DBL}}=1.0 \mathrm{~mm}, J_{\mathrm{O}_{2}}=$ $6.9 \mathrm{mmol} \mathrm{m}^{-2} \mathrm{~d}^{-1}$, and $M_{\mathrm{O}_{2}}=54 \mu \mathrm{mol} \mathrm{m}^{-2}$ ). Conversely, $z_{\max }$ decreased to a minimum of $0.3 \mathrm{~mm}$ and $C_{\mathrm{SWI}}$ 

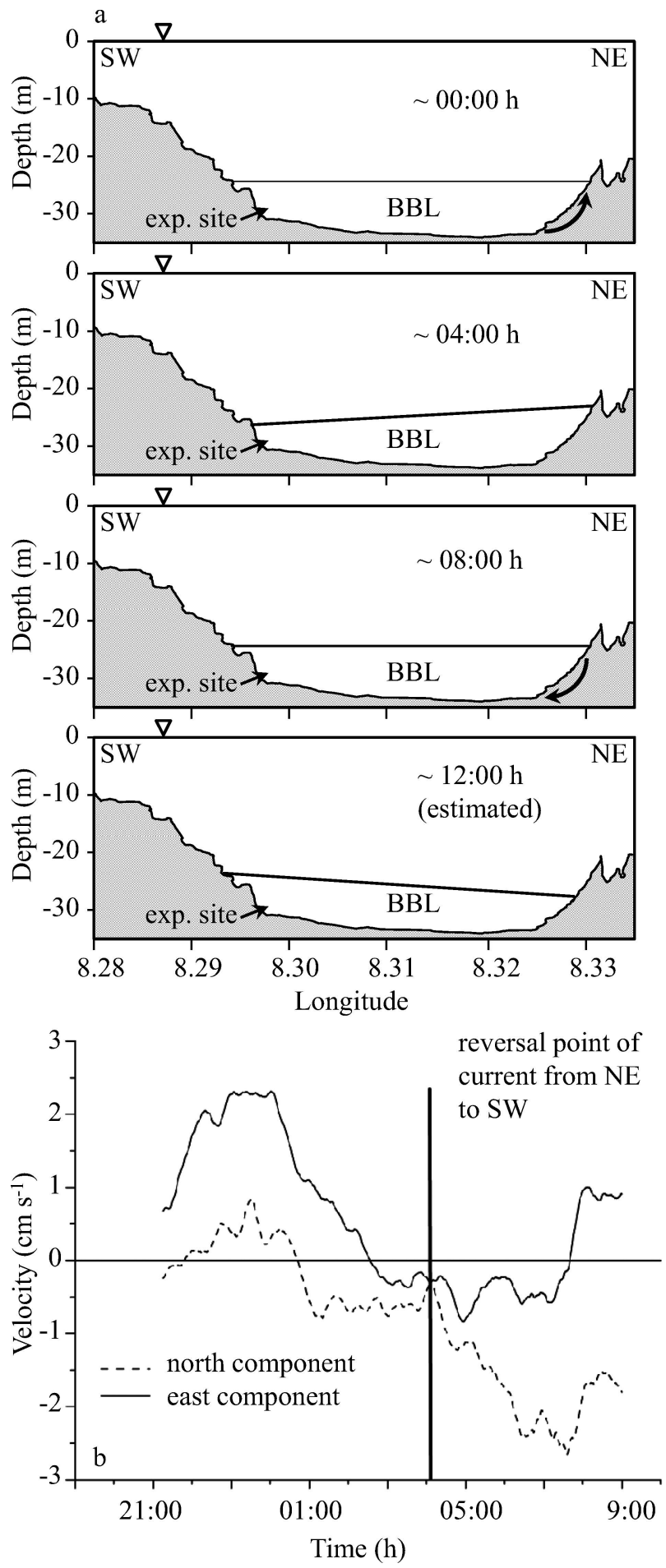

Fig. 3. (a) Seiche cycle in Lake Alpnach and location of experiment site during 27-28 August 2007 campaign. Note that water surface is indicated by downward-facing triangles and that scale of seiche is approximate. (b) East and north velocity components at $10 \mathrm{~cm}$ above the sediment as measured by the ADV. Bold vertical line marks the current reversal point where seiche-induced motion of the waterbody changed direction from northeast (NE) to southwest (SW). decreased from 59 to $5 \mu \mathrm{mol} \mathrm{L}^{-1}$ during negligible turbulence (corresponding $\delta_{\mathrm{DBL}}=7.6 \mathrm{~mm}, J_{\mathrm{O}_{2}}=$

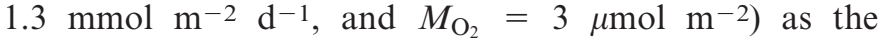
sediment approached anoxia. The strongly coupled behavior observed in these parameters is supported by recent modeling work based on data from Lake Alpnach (Brand et al. 2009), which shows that an increase in $\delta_{\mathrm{DBL}}$ (from 0.25 to $1.5 \mathrm{~mm}$ ) results in decreased $z_{\max }$ (from 1.7 to $1.2 \mathrm{~mm}$ ) and decreased $J_{\mathrm{O}_{2}}$ (from 15 to $9.5 \mathrm{mmol} \mathrm{m}^{-2} \mathrm{~d}^{-1}$ ).

Profile dynamics -Eq. 2 was used to determine proximity to steady state. Although significant variation was observed in our $\mathrm{O}_{2}$ profiles over the 12-h measurement period (Fig. 5), $\mathrm{O}_{2}$ accumulation and/or depletion within the sediment was insignificant (Table 4), with an average $\partial C / \partial t_{a}$ of $\pm 0.30 \mathrm{mmol} \mathrm{m}^{-2} \mathrm{~d}^{-1}$, or $\sim 5 \%$ of the average $J_{\mathrm{O}_{2}}$ $\left(5.2 \mathrm{mmol} \mathrm{m}^{-2} \mathrm{~d}^{-1}\right)$ over the full measurement period. The rate at which $\mathrm{O}_{2}$ enters the sediment $\left(J_{\mathrm{O}_{2}}\right)$ equals the areal $\mathrm{O}_{2}$ consumption rate $\left(R_{\mathrm{O}_{2} a}\right)$ at steady state (Eq. 2$)$, and these values were found to be almost equivalent in our mesotrophic lake system (Table 4). Additionally, the average $J_{\mathrm{O}_{2}}$ and $M_{\mathrm{O}_{2}}\left(32 \mu \mathrm{mol} \mathrm{m}{ }^{-2}\right.$; Table 4$)$ for the 12 -h period indicate a mean $\mathrm{O}_{2}$ residence time in the sediment of $9 \mathrm{~min}$. Because profiles were obtained every $\sim 50 \mathrm{~min}$, quasi-steady-state conditions prevailed.

\section{Discussion}

Forcing of $\mathrm{O}_{2}$ distribution-Lorke et al. (2003) show that $\delta_{\text {DBL }}$ is controlled primarily by turbulence rather than velocity based on an observed phase lag between $\varepsilon, \delta_{\mathrm{DBL}}$, and current velocity, where $\varepsilon$ and $\delta_{\mathrm{DBL}}$ lagged consistently $(\sim 1.5 \mathrm{~h})$ behind current velocity at $1 \mathrm{~m}$ above the sediment. Although we do observe a direct relationship between $\varepsilon$ and $\delta_{\mathrm{DBL}}$, a defined phase lag between these parameters and current velocity was not evident within the temporal resolution of our measurements (Fig. 7). However, it has been shown that this delay becomes greater with increasing distance from the sediment (Lorke et al. 2002). The phase lag would therefore be expected to be much shorter $(\sim 10 \mathrm{~min})$ during our experiment.

During periods of relatively high velocity (profiles $1-5$ and 9-14), turbulence increased as cold water from the deeper region of the BBL moved across our experiment site (Figs. 4, 7). The movement of this cooler water mass along the slope may have established small inverse temperature gradients that produced additional turbulence due to bottom convective mixing (Lorke et al. 2005). Turbulence compressed the DBL during these periods, which facilitated increased $\mathrm{O}_{2}$ transport from the BBL down to the sediment and resulted in greater sediment $\mathrm{O}_{2}$ uptake and an enhanced sediment oxic zone. As the water mass approached current reversal (profiles 5-9), decreased turbulence, $J_{\mathrm{O}_{2}}$, and $z_{\max }$ are observed as current velocity subsided (Figs. 5, 6).

Temperatures in the BBL and near the SWI increased (Fig. $4 \mathrm{a}-\mathrm{c}$ ) in response to the influx of warm water from farther up the slope (confirmed by CTD data, not shown). Variations in temperature are reflected over the full microsensor profile depth and are not affected by changes 


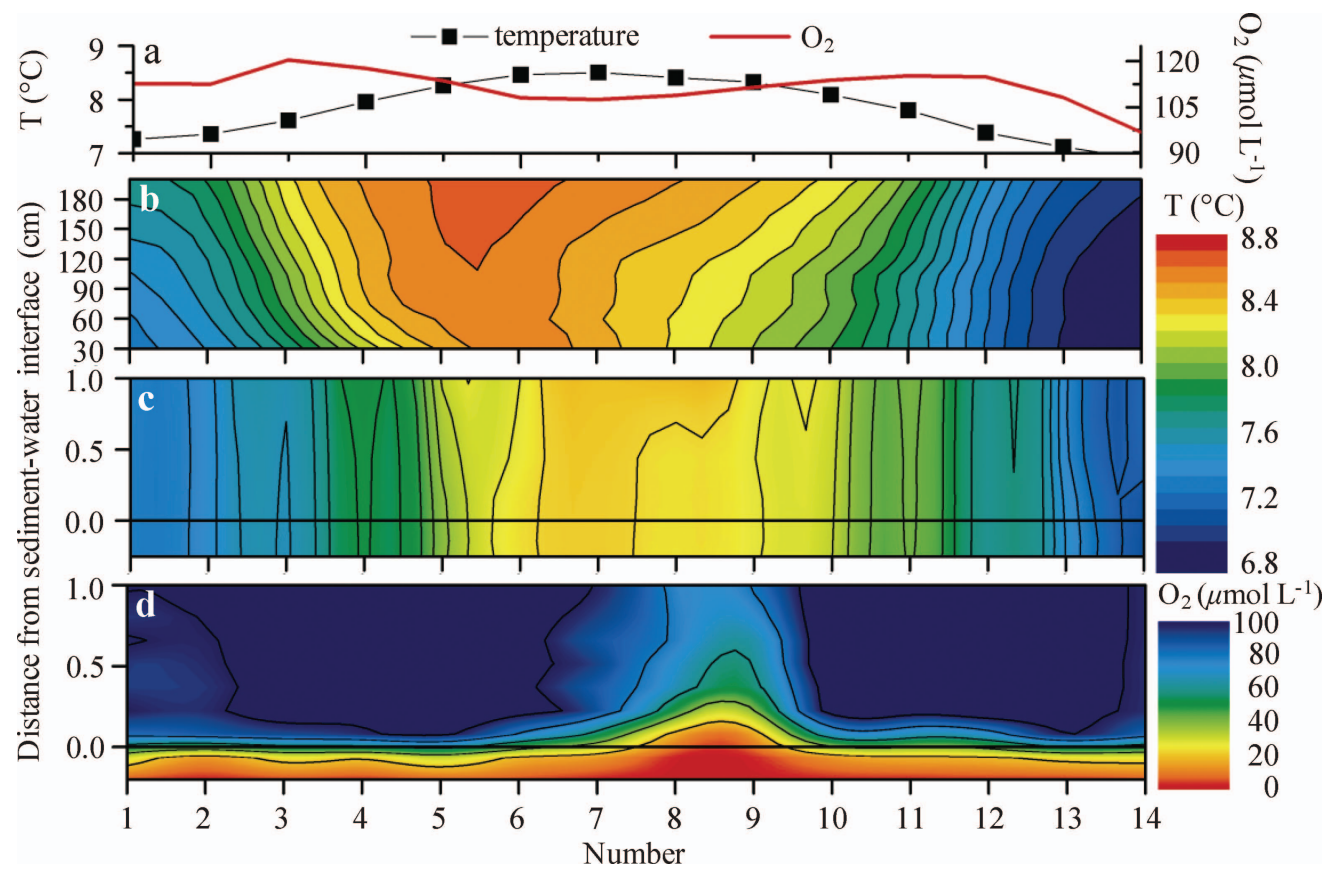

Fig. 4. Temperature and $\mathrm{O}_{2}$ data obtained on 27-28 August 2007. (a) Temperature $(T)$ and $\mathrm{O}_{2}$ time series as measured using a $T$-O logger at $8 \mathrm{~cm}$ above sediment. (b) Temperature contour plot showing data from $30 \mathrm{~cm}$ to $200 \mathrm{~cm}$ above sediment as measured via thermistors. (c and d) Temperature and $\mathrm{O}_{2}$ contour plots showing data from $-0.25 \mathrm{~cm}$ (in sediment) up to $1 \mathrm{~cm}$ (in water) as measured via microprofiler microsensors (14 profiles throughout 12-h measurement period).

in $\delta_{\mathrm{DBL}}$, which is likely due to the relatively rapid rate of heat transfer (compared to molecular diffusion) and the fact that temperature is not consumed by the sediment (unlike $\mathrm{O}_{2}$ ). Hence, once the near-surface sediment temperature equilibrates with that of the BBL, the sediment no longer behaves as a heat sink. Conversely, significant variation was observed in the vertical distribution of $\mathrm{O}_{2}$ across the SWI, which may be largely attributed to $\mathrm{O}_{2}$ consumption. In the absence of turbulence, while $\mathrm{O}_{2}$ remained at $\sim 110 \mu \mathrm{mol} \mathrm{L}-1$ several centimeters above the SWI, the $\mathrm{O}_{2}$ supply through the extended DBL was insufficient to maintain the sediment oxic zone (Figs. 4, 6). As $J_{\mathrm{O}_{2}}$ diminished and $\mathrm{O}_{2}$ was consumed in the sediment, $\mathrm{O}_{2}$ in the water immediately overlying the sediment, $C_{\text {SWI }}$, and $z_{\max }$ decreased significantly (Figs. 4, 5). These findings emphasize that, even when $\mathrm{O}_{2}$ levels in the $\mathrm{BBL}$ remain relatively high, the $\mathrm{O}_{2}$ distribution on both sides of the SWI and the corresponding $J_{\mathrm{O}_{2}}$ are strongly governed by turbulence, as supported by previous work (Jørgensen and Revsbech 1985; Brand et al. 2009; Gantzer et al. 2009a).

Variations in sediment $\mathrm{O}_{2}$ consumption-Quasi-steadystate conditions prevailed $\left(J_{\mathrm{O}_{2}}\right.$ and $R_{\mathrm{O}_{2} a}$ differed by only $5 \%$ ) and, correspondingly, both $J_{\mathrm{O}_{2}}$ and $R_{\mathrm{O}_{2}}$ (quantified by $R_{\mathrm{O}_{2} a}$ and $R_{\mathrm{O}_{2} v}$ ) varied in response to dynamic forcing, as shown by $R_{\mathrm{O}_{2} a}$ data in Table 4 . This indicates that sediment $\mathrm{O}_{2}$ consumption was directly related to $\mathrm{O}_{2}$ availability within the sediment as supplied via $J_{\mathrm{O}_{2}}$. Monod and firstorder kinetic models are used to characterize sediment $\mathrm{O}_{2}$ consumption as a function of $\mathrm{O}_{2}$ concentration in the sediment (Rasmussen and Jørgensen 1992; Higashino et al. 2004). However, due to the variety of $\mathrm{O}_{2}$-consuming processes and the complexity of the kinetics, simple zeroorder kinetics is frequently assumed (Bouldin 1968; Jørgensen and Boudreau 2001; Røy et al. 2004). Irrespective of the kinetics, though, it has been reported that when $\mathrm{O}_{2}$ uptake is at least partially governed by diffusive transport, $R_{\mathrm{O}_{2}}$ does become dependent on $\mathrm{O}_{2}$ concentration below $\mathrm{O}_{2}$ levels of $20-30 \mu \mathrm{mol} \mathrm{L}{ }^{-1}$ (Santschi et al. 1990; Berg et al. 2003). Sediment $\mathrm{O}_{2}$ levels remained close to this minimum range during our study (Fig. 5). Our results therefore demonstrate dependence of $R_{\mathrm{O}_{2}}$ on $\mathrm{O}_{2}$ availability under limiting $\mathrm{O}_{2}$ conditions regardless of the kinetics involved. Models based on variable zones of $\mathrm{O}_{2}$ consumption and Monod kinetics were used (zonefit and model methods, respectively) to evaluate $J_{\mathrm{O}_{2}}$ and $\delta_{\mathrm{DBL}}$ with comparable results (Table 3; L. Bryant unpubl. data).

Variability in sediment $\mathrm{O}_{2}$ consumption was further evaluated using PROFILE (zonefit method) to characterize regions of differing $R_{\mathrm{O}_{2} v}$ within the sediment oxic zone as a function of time and depth, as shown in Fig. 8. Zonespecific $R_{\mathrm{O}_{2} v}$ values predicted by PROFILE were corrected for $\partial C / \partial t_{v}$ (Eq. 2). PROFILE results show that $R_{\mathrm{O}_{2} v}$ was consistently higher near the SWI and then decreased significantly with depth (Fig. 8). Results by O'Connor and Harvey (2008) and Brand et al. (2009) also show increased $R_{\mathrm{O}_{2} v}$ immediately below the SWI. $\mathrm{O}_{2}$ consumption in the upper sediment region is often elevated as a result of mineralization of freshly deposited organic matter at the sediment surface as well as reoxidation of subsequently released reduced inorganic species (Santschi et al. 1990; Zhang et al. 1999). Accordingly, increased heterotrophic bacterial abundance and activity in the sediment surface layer is common (Fischer et al. 2002, 2005). 

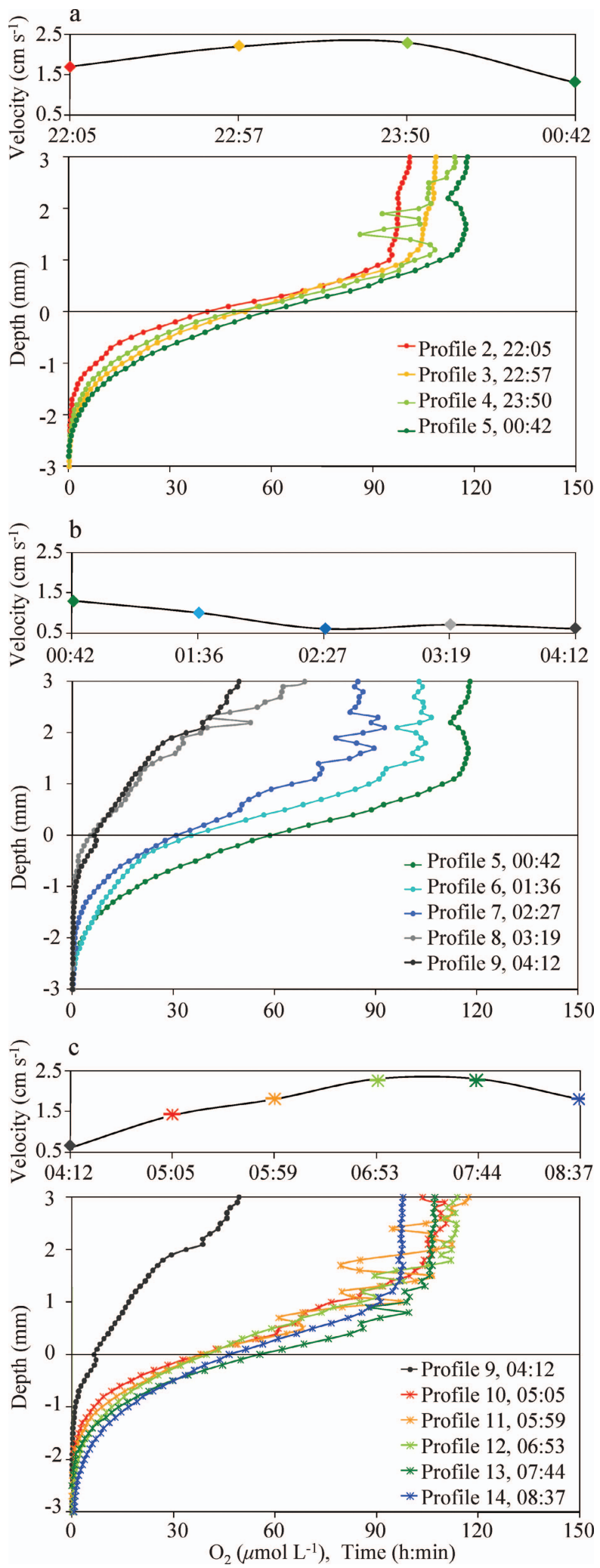

Fig. 5. $\mathrm{O}_{2}$ microprofiles obtained at approximately 50-min intervals relative to the ADV velocity time series. $\mathrm{O}_{2}$ profiles are divided into three panels with corresponding section of velocity time series plotted above each $\mathrm{O}_{2}$ profile panel (a-c). (a) Initially, current velocity is increasing and the $\mathrm{O}_{2}$ profiles are observed to shift to the right toward more oxic conditions in both the water
Variations in turbulence (Fig. 8a) coupled with changes in PROFILE-predicted consumption zones (Fig. 8b-d) support our observation of increased $J_{\mathrm{O}_{2}}$ leading to increased $\mathrm{O}_{2}$ consumption (Table 4). The upper sediment layer is obviously most directly affected by turbulence in the BBL and variations in $\delta_{\mathrm{DBL}}$. Consumption in this upper zone is observed to increase during periods of peak turbulence when elevated $\mathrm{O}_{2}$ concentrations above the sediment and a thinner $\delta_{\mathrm{DBL}}$ facilitate enhanced $J_{\mathrm{O}_{2}}$. Elevated $R_{\mathrm{O}_{2} v}$ in the upper sediment as a result of increased $\mathrm{O}_{2}$ availability implies that the intrinsic capacity of the sediment for $\mathrm{O}_{2}$ consumption (PSOD) exceeds $J_{\mathrm{O}_{2}}$, indicating water-side control of sediment $\mathrm{O}_{2}$ uptake (O'Connor and Harvey 2008). When $J_{\mathrm{O}_{2}}$ increased in response to elevated turbulence, the sediment oxic zone is observed to increase while $\partial C / \partial t_{a}$ remained relatively small; this supports that the additional $\mathrm{O}_{2}$ entering the sediment was being consumed rather than accumulating in the sediment (Fig. 8b,d; Table 4). During the period when turbulence is at a minimum and $\delta_{\mathrm{DBL}}$ extends to the point of becoming undefined, thereby limiting $\mathrm{O}_{2}$ transport and subsequent availability at the SWI, consumption is characterized by a minimal zone and $R_{\mathrm{O}_{2} v}$ drops significantly (Fig. 8c). At this point, the sediment oxic zone almost completely disappears. The elasticity observed in sediment-water $\mathrm{O}_{2}$ profiles shown in Fig. 5 is also evident in sediment $\mathrm{O}_{2}$ consumption zones shown in Fig. 8, although it is less direct because of the complexity of sediment processes. The distribution of $\mathrm{O}_{2}$ consumption zones for profile 13 (Fig. 8d) returns to a structure similar to that of profile 4 (Fig. 8b) when turbulence increases after a substantial shift to a smaller, single zone for profile 8 during the stagnant period (Fig. 8c).

Our results show that variations in $\delta_{\mathrm{DBL}}$ have a significant effect on $J_{\mathrm{O}_{2}}, R_{\mathrm{O}_{2}}$ (both areally and volumetrically), and resultant $z_{\max }$. It is important to emphasize that in this study, diffusion time for $\mathrm{O}_{2}$ across the DBL and transport time through the sediment oxic zone are comparable $(\sim 10$ to $20 \mathrm{~min}$ during the majority of the campaign when turbulence levels were high enough to maintain a defined DBL). When the timescale of $\mathrm{O}_{2}$ diffusion through the DBL is short in comparison to transport through the sediment oxic zone (e.g., oligotrophic environments where $z_{\max }$ can be measured in centimeters and sediment $\mathrm{O}_{2}$ residence time can be on the order of days), changes in $\delta_{\mathrm{DBL}}$ would be unlikely to have a strong influence on $J_{\mathrm{O}_{2}}, R_{\mathrm{O}_{2}}$, and $z_{\max }$ (Glud et al. 2007).

Scale of variation-Mean values for $J_{\mathrm{O}_{2}}$ (Table 4) obtained during this study are comparable to values found

$\leftarrow$

and the sediment with a corresponding decrease in $\delta_{\mathrm{DBL}}$ and increase in $z_{\max }$. (b) As velocity decreases, $\delta_{\mathrm{DBL}}$ is shown to increase and $z_{\max }$ to decrease as the profiles shift to the left toward anoxic conditions in the sediment and overlying water. (c) As velocities return to initial levels, the $\mathrm{O}_{2}$ profiles are observed to shift back to the right toward a more oxic distribution similar to that observed in (a). 


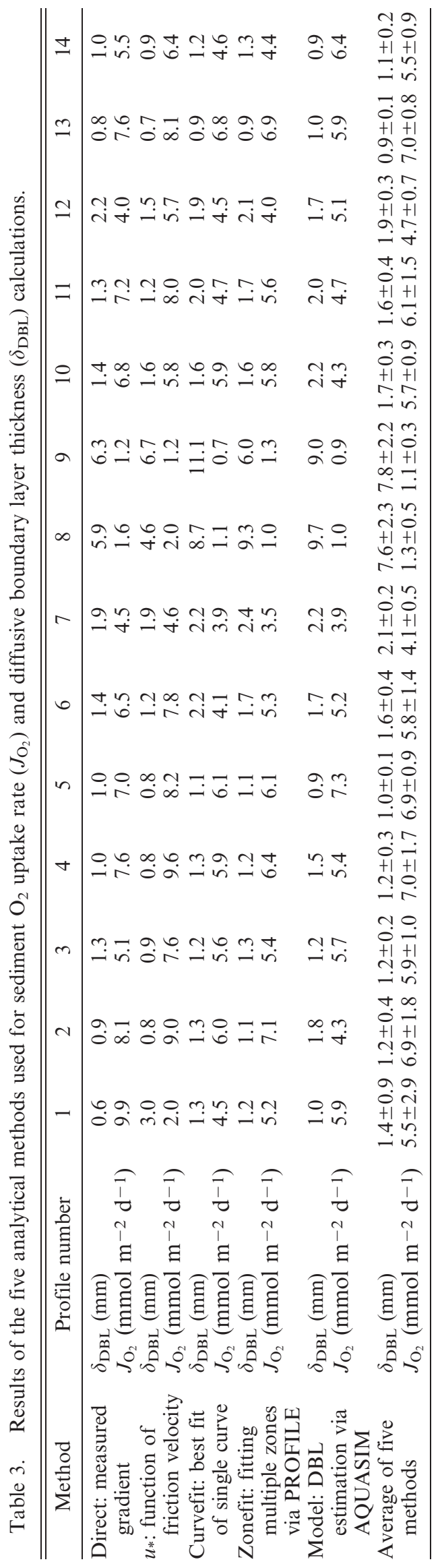

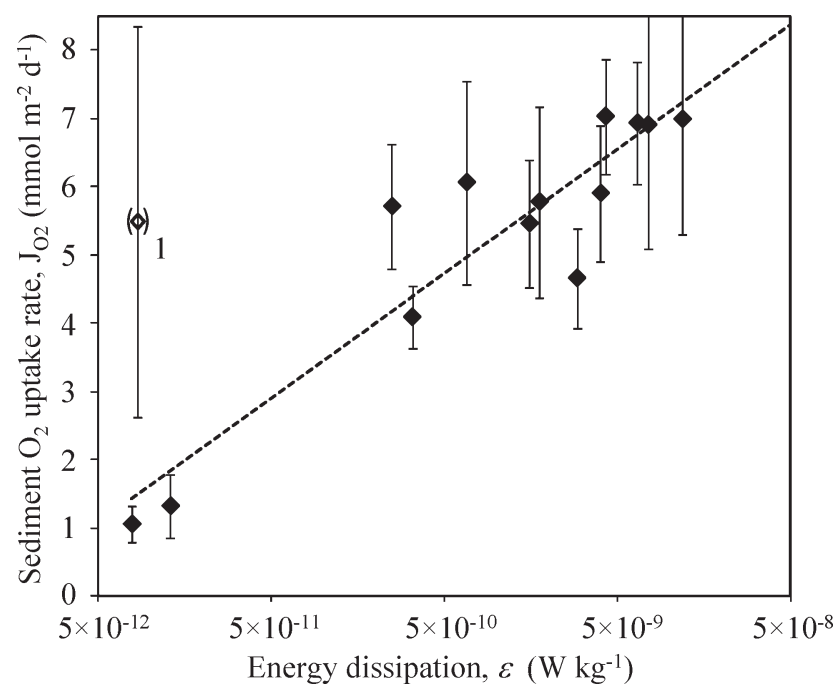

Fig. 6. Correlation between $\varepsilon$ and sediment $\mathrm{O}_{2}$ uptake rate $\left(J_{\mathrm{O}_{2}}\right)$. The linear trendline serves as a guide for the reader's eye and does not imply an explicit relationship between $J_{\mathrm{O}_{2}}$ and $\varepsilon$. Because data for profile 1 are outliers, as discussed in the text, these data are placed in parentheses.

in previous studies of BBL turbulence at the same location. Brand et al. (2008) estimated an average $J_{\mathrm{O}_{2}}$ of $13 \pm$ $2 \mathrm{mmol} \mathrm{m}-2 \mathrm{~d}^{-1}$ and Lorke et al. (2003) estimated $J_{\mathrm{O}_{2}}$ to range from 6 to $13 \mathrm{mmol} \mathrm{m} \mathrm{m}^{-2} \mathrm{~d}^{-1}$, with a corresponding $\delta_{\text {DBL }}$ range of 0.16 to $0.84 \mathrm{~mm}$. Turbulence and $\mathrm{O}_{2}$ levels in the BBL were higher in these previous studies than those observed during our campaign; this is reflected in our relatively low turbulence estimates and subsequently decreased $J_{\mathrm{O}_{2}}$ and increased $\delta_{\mathrm{DBL}}$ values. Despite the less energetic conditions, variation in $J_{\mathrm{O}_{2}}$ and the vertical

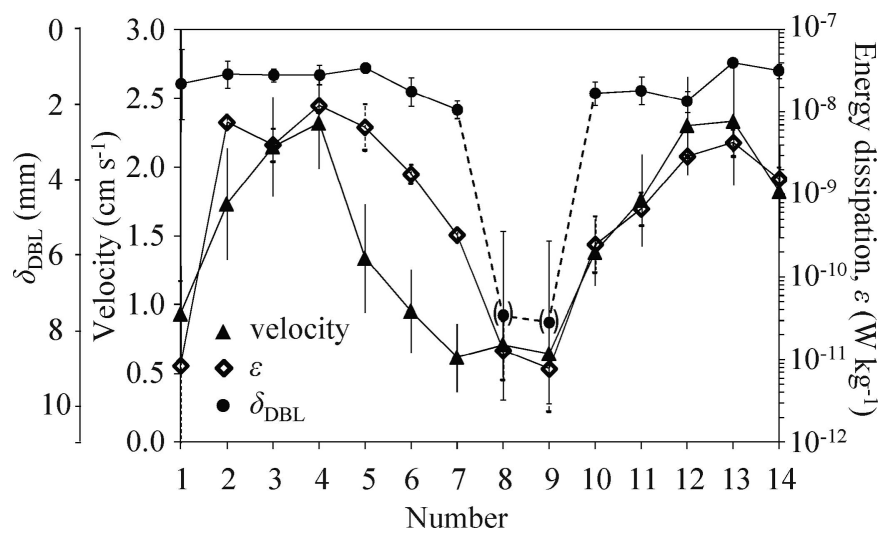

Fig. 7. Time series of current velocity, turbulence (as defined by $\varepsilon$ ), and $\delta_{\mathrm{DBL}}$ showing close correlation between all three parameters with only a slight phase lag (on the order of minutes) between velocity and $\varepsilon$. Similarity in $\delta_{\mathrm{DBL}}$ estimates obtained from different analytical methods is indicated by low standard deviations for $\delta_{\mathrm{DBL}}$. The DBL becomes undefined during the period of negligible turbulence and thus corresponding $\delta_{\mathrm{DBL}}$ data (profiles 8 and 9) are placed in parentheses with dashed-line connectors to emphasize that these data are included solely as a relative comparison. Note reversed axis for $\delta_{\mathrm{DBL}}$. 
Table 4. Average $J_{\mathrm{O}_{2}}$ and vertically integrated areal rates of change in the $\mathrm{O}_{2}$ concentration over time $\left(\partial C / \partial t_{a}\right)$, areal sediment $\mathrm{O}_{2}$ consumption rates $\left(R_{\mathrm{O}_{2} a}\right)$, and mass of $\mathrm{O}_{2}\left(M_{\mathrm{O}_{2}}\right)$ in the sediment.

\begin{tabular}{|c|c|c|c|c|}
\hline Profile number & 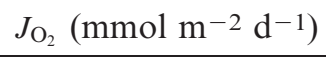 & $\partial C / \partial t_{a}{ }^{*} \dagger\left(\mathrm{mmol} \mathrm{m}^{-2} \mathrm{~d}^{-1}\right)$ & 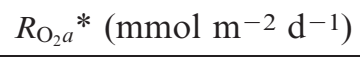 & $M_{\mathrm{O}_{2}} *(\mu \mathrm{mol} \mathrm{m}-2)$ \\
\hline 2 & 6.9 & -0.11 & 7.0 & 26 \\
\hline 3 & 5.9 & 0.14 & 5.8 & 42 \\
\hline 4 & 7.0 & 0.16 & 6.8 & 36 \\
\hline 5 & 6.9 & -0.02 & 7.0 & 54 \\
\hline 6 & 5.8 & -0.42 & 6.2 & 34 \\
\hline 7 & 4.1 & -0.44 & 4.5 & 23 \\
\hline 10 & 5.7 & 0.31 & 5.4 & 24 \\
\hline 11 & 6.1 & 0.11 & 6.0 & 28 \\
\hline 12 & 4.7 & 0.16 & 4.5 & 32 \\
\hline 13 & 7.0 & 0.17 & 6.9 & 40 \\
\hline 14 & 5.5 & 0.11 & 5.3 & 44 \\
\hline Average & 5.2 & \pm 0.30 & 5.3 & 32 \\
\hline
\end{tabular}

* Profile-specific areal values of $R_{\mathrm{O}_{2} a}, \partial C / \partial t_{a}$, and $M_{\mathrm{O}_{2}}$ represent the integral over the depth of the sediment oxic zone. $\partial C / \partial t_{a}$ was evaluated for each profile as follows: the profiles immediately before and after were compared (e.g., profiles 2 and 4 were compared to evaluate profile 3 ) to calculate the areal rate of change in $\mathrm{O}_{2}\left(\partial \mathrm{C} / \partial \mathrm{t}_{a}\right)$.

$\uparrow$ Quasi-steady state is established by relatively insignificant values of $\partial C / \partial t_{a}\left(5 \%\right.$ of average $\left.J_{\mathrm{O}_{2}}\right)$.

distribution of $\mathrm{O}_{2}$ over the 12-h measurement period was still significant (Figs. 5-7). The fact that we observed such change in these parameters in response to dynamic, though relatively mild, turbulence conditions highlights the dependence of sediment $\mathrm{O}_{2}$ uptake on turbulence.

Not only was $J_{\mathrm{O}_{2}}$ found to vary significantly over the duration of a single seiche cycle (on the order of hours) during our campaign (Fig. 6), but it was also observed to change substantially on a subhourly timescale. For example, in the course of the 53-min period between profiles 9 and 10 when turbulence increased as the waterbody shifted back toward the southwest direction following current reversal, $J_{\mathrm{O}_{2}}$ increased from $1.1 \mathrm{mmol} \mathrm{m}^{-2} \mathrm{~d}^{-1}$ to $5.7 \mathrm{mmol} \mathrm{m}^{-2} \mathrm{~d}^{-1}$ (Table 4). During this time, $\varepsilon$ increased from $7.8 \times 10^{-12}$ to $2.5 \times 10^{-10} \mathrm{~W} \mathrm{~kg}-1, \delta_{\text {DBL }}$ decreased from 7.8 to $1.7 \mathrm{~mm}$ (Fig. 7), $z_{\max }$ increased from 0.6 to $1.3 \mathrm{~mm}$ (Fig. 5), and $M_{\mathrm{O}_{2}}$ increased from 5 to $24 \mu \mathrm{mol} \mathrm{m}^{-2}$ (Table 4). The high degree of variation observed in $J_{\mathrm{O}_{2}}$ and the vertical $\mathrm{O}_{2}$ distribution over such a brief time period illustrates the transient nature of sediment $\mathrm{O}_{2}$ uptake. While it has been shown that longterm (e.g., annual) average $J_{\mathrm{O}_{2}}$ is typically not influenced by short-term (e.g., hourly) changes in $\delta_{\mathrm{DBL}}$ (Glud et al. 2007), our results stress the importance of taking turbulence into account when resolving $\mathrm{O}_{2}$ profiles in order to fully evaluate $J_{\mathrm{O}_{2}}$. Under dynamic conditions, a system must be characterized in greater detail than what can be discerned from a single profile. An accurate assessment of $J_{\mathrm{O}_{2}}$ and $R_{\mathrm{O}_{2}}$ is not possible without obtaining a comprehensive series of profiles describing the full range of variation in the vertical distribution of $\mathrm{O}_{2}$. Furthermore, extreme caution should be taken in evaluating PSOD based on $R_{\mathrm{O}_{2} v}$ analyses without considering physical limitations on $\mathrm{O}_{2}$ transport to the SWI (and subsequent $\mathrm{O}_{2}$ availability in the sediment) and proximity to long-term steady state. Variation in PROFILE-predicted $R_{\mathrm{O}_{2} v}$ results for individual profiles (Fig. 8) emphasizes how evaluating $R_{\mathrm{O}_{2} v}$ based on a single profile could lead to very different estimates of PSOD. In all likelihood, the average $R_{\mathrm{O}_{2} v}$ observed during our 12-h campaign (3.5 mmol m $\mathrm{m}^{-3} \mathrm{~d}^{-1}$ in upper sediment; data not shown) may still significantly underestimate actual PSOD due to the mild turbulence conditions limiting sediment $\mathrm{O}_{2}$ availability and subsequent consumption.

Technical and logistical restraints often limit the number of in situ microsensor measurements obtained during a given deployment to only a few (Glud et al. 2009), which may be an issue depending on the timescale of the dynamics in the system of interest. During this study, we were able to obtain 14 microprofiles at approximately 50-min intervals. Fluctuations in $\delta_{\mathrm{DBL}}$ have been previously observed at timescales on the order of seconds (Røy et al. 2004; O'Connor and Hondzo 2008). However, Brand et al. (2009) show that the influence of these rapid variations in $\delta_{\mathrm{DBL}}$ is negligible on evaluations of mean $J_{\mathrm{O}_{2}}$ and the vertical $\mathrm{O}_{2}$ distribution near the SWI at timescales appropriate for defining seiche cycles (e.g., minutes, hours). The subhourly timescale at which we assessed data is small compared to the 8-h duration of the seiche cycle; thus, a thorough characterization of how seiche-induced variations in sediment $\mathrm{O}_{2}$ uptake was achieved.

In conclusion, our results reveal the effect of natural dynamic forcing on the vertical distribution of $\mathrm{O}_{2}$ across the SWI and on sediment $\mathrm{O}_{2}$ uptake. Although work has been done that contributes significantly to the understanding of BBL dynamics and flux pathways, these studies have been largely laboratory or model based (Røy et al. 2004; Glud et al. 2007; O'Connor and Hondzo 2008). Previous in situ studies have focused primarily on physical, water-side controls of $\mathrm{O}_{2}$ transport (Gundersen and Jørgensen 1990; Lorke et al. 2003) or spatial and temporal variations in $\mathrm{O}_{2}$ distribution in sediment (Epping and Helder 1997; Glud et al. 2003, 2009). This study is novel in that we analyzed $\mathrm{O}_{2}$ uptake from both sides of the SWI. In doing so, we have 

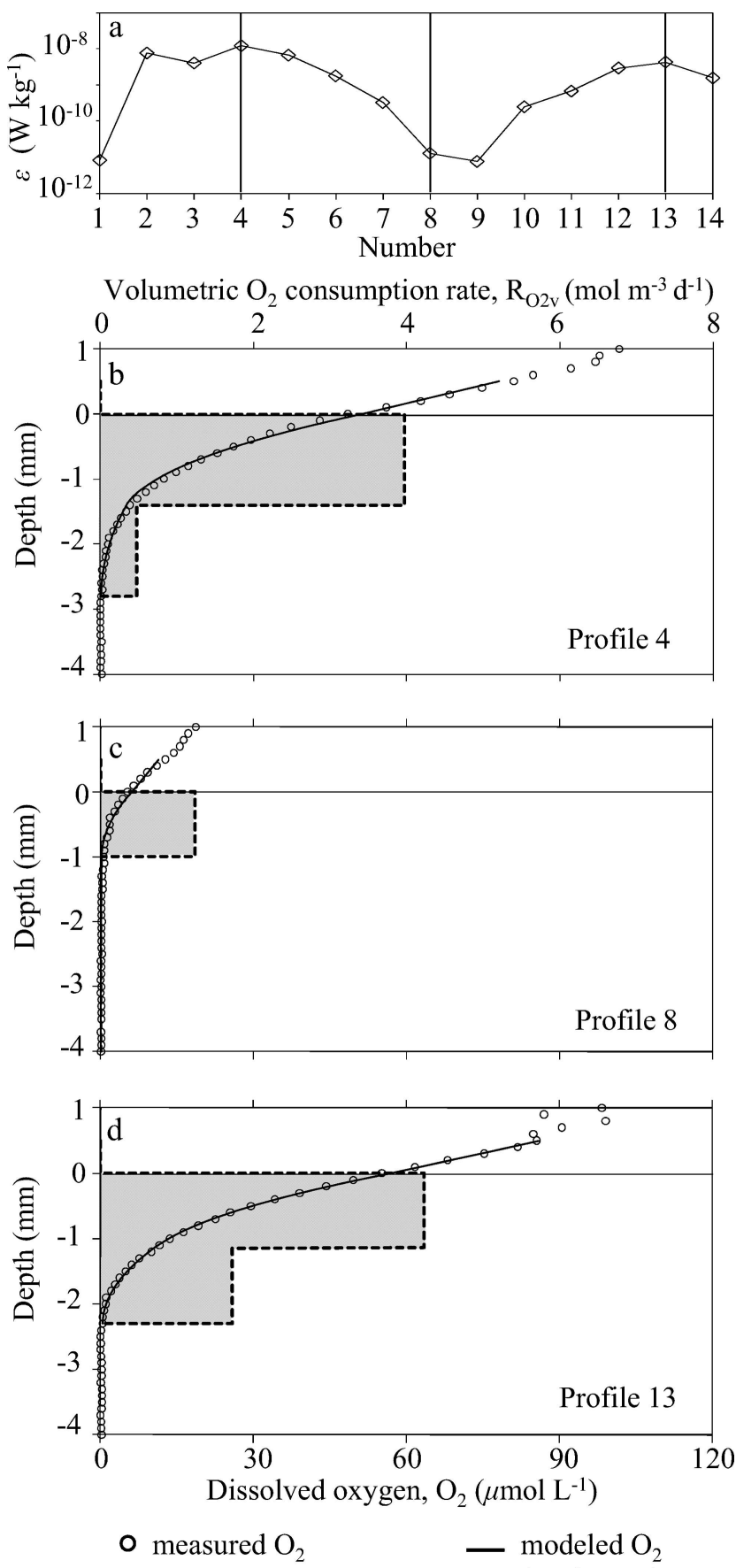

(PROFILE)

energy dissipation, $\varepsilon \quad[-.-$ consumption

(PROFILE)

Fig. 8. PROFILE model results defining zones of varying volumetric sediment $\mathrm{O}_{2}$ consumption rates $\left(R_{\mathrm{O}_{2} v}\right)$ for periods of active and inactive turbulence as characterized by $\varepsilon$ in (a). During elevated turbulence ( $b$ and $d$ ), $\mathrm{O}_{2}$ consumption is characterized by two zones. However, a single zone defines low consumption during the period of negligible turbulence (c).

expanded on previous results by analyzing the tight coupling between water-side (turbulence, as characterized by $\varepsilon)$ and sediment-side $\left(\mathrm{O}_{2}\right.$ consumption in sediment, as characterized by $R_{\mathrm{O}_{2}}$ ) processes influencing sediment $\mathrm{O}_{2}$ uptake under actual field conditions in a freshwater system. The highly transient nature of $J_{\mathrm{O}_{2}}$ is revealed by rapid changes in the vertical distribution of $\mathrm{O}_{2}$ in both the water and the sediment in response to dynamic forcing via seiche motion. $R_{\mathrm{O}_{2}}$ was shown to adjust quickly to variations in $J_{\mathrm{O}_{2}}$ at quasi-steady state. Although our study focused on $\mathrm{O}_{2}$ fluxes, knowledge gained regarding the relationship between turbulence and mass transfer at the SWI can be more broadly applied to fluxes of other soluble chemical species (e.g., reduced metals, hydrogen sulfide, methane) as well (Jørgensen et al. 1979; Frenzel et al. 1990; Gantzer et al. 2009b). The crucial role of turbulence is highlighted by the fact that, despite relatively high $\mathrm{O}_{2}$ levels only a few centimeters above the sediment, $\mathrm{O}_{2}$ transport to the SWI and the extent of the sediment oxic zone both decreased substantially during quiescent periods. The critical control that dynamic forcing can have on $J_{\mathrm{O}_{2}}$ must be considered when evaluating sediment $\mathrm{O}_{2}$ uptake via measuring devices (e.g., benthic chambers) that do not capture natural turbulence conditions. Furthermore, based on the significant changes observed in $J_{\mathrm{O}_{2}}$ during periods as brief as an hour, our results show that using isolated $J_{\mathrm{O}_{2}}$ measurements may be insufficient, particularly in systems experiencing high levels of variable turbulence.

\section{Acknowledgments}

We are grateful to Peter Berg and Miki Hondzo for their useful advice. We also thank Lorenzo Rovelli, Michi Schurter, Christian Dinkel, and Mathias Kirf, who offered invaluable assistance in the field and with equipment. Helpful feedback from Ronnie Glud, Hans Røy, and an anonymous reviewer substantially improved the manuscript. The research described in this paper has been funded in part by the U.S. Environmental Protection Agency (EPA) under the Science to Achieve Results (STAR) Graduate Fellowship Program. The EPA has not officially endorsed this publication, and the views expressed herein may not reflect the views of the EPA. This research was also supported by the U.S. National Science Foundation (NSF) through the Integrative Graduate Education and Research Traineeship (IGERT) program (DGE 0504196) and by the Swiss National Science Foundation, grants 200020-111763 and 200020-120128.

\section{References}

Arega, F., And J. H. W. Lee. 2005. Diffusional mass transfer at sediment-water interface of cylindrical sediment oxygen demand chamber. J. Environ. Eng.-ASCE 131: 755-766, doi:10.1061/(ASCE)0733-9372(2005)131:5(755)

Baker, M. A., AND C. H. Gibson. 1987. Sampling turbulence in the stratified ocean: Statistical consequences of strong intermittency. J. Phys. Oceanogr. 17: 1817-1836, doi:10.1175/1520-0485 (1987)017<1817:STITSO > 2.0.CO;2

Berg, P., N. Risgaard-Petersen, and S. Rysgaard. 1998. Interpretation of measured concentration profiles in sediment pore water. Limnol. Oceanogr. 43: 1500-1510.

—, S. Rysgaard, and B. Thamdrup. 2003. Dynamic modeling of early diagenesis and nutrient cycling. A case study in an arctic marine sediment. Am. J. Sci. 303: 905-955, doi:10.2475/ajs.303.10.905

Beutel, M. W. 2003. Hypolimnetic anoxia and sediment oxygen demand in California drinking water reservoirs. Lake Reserv. Manage. 19: 208-221, doi:10.1080/07438140309354086 
Boudreau, B. P. 2001. Solute transport above the sediment-water interface, p. 104-126. In B. P. Boudreau and B. B. Jørgensen [eds.], The benthic boundary layer: Transport processes and biogeochemistry. Oxford Univ. Press.

Bouldin, D. R. 1968. Models for describing the diffusion of oxygen and other mobile constituents across the mud-water interface. J. Ecol. 56: 77-87, doi:10.2307/2258068

Brand, A., C. Dinkel, and B. Wehrli. 2009. Influence of the diffusive boundary layer on the solute dynamics in the sediments of a seiche-driven lake: A model study. J. Geophys. Res. 114, G01010, doi:10.1029/2008JG000755

—, D. F. McGinnis, B. Wehrli, and A. Wüest. 2008. Intermittent oxygen flux from the interior into the bottom boundary of lakes as observed by eddy correlation. Limnol. Oceanogr. 53: 1997-2006.

— AND OTHERS. 2007. Microsensor for in situ flow measurements in benthic boundary layers at submillimeter resolution with extremely slow flow. Limnol. Oceanogr. Methods 5: 185-191.

DalsgaArd, T. AND others [EDs.]. 2000. Protocol handbook for NICE - Nitrogen Cycling in Estuaries: A project under the EU research programme: Marine Science and Technology (MAST III). National Environmental Research Institute, Silkeborg, Denmark, http://www2.dmu.dk/LakeandEstuarineEcology/ nice/NICE_handbook.pdf.

Epping, E. H. G., AND W. Helder. 1997. Oxygen budgets calculated from in situ microprofiles for Northern Adriatic sediments. Cont. Shelf Res. 17: 1737-1764, doi:10.1016/ S0278-4343(97)00039-3

Fischer, H., F. Kloep, S. Wilzcek, and M. T. Pusch. 2005. A river's liver-microbial processes within the hyporheic zone of a large lowland river. Biogeochemistry 76: 349-371, doi:10.1007/s10533-005-6896-y

_- S. C. Wanner, And M. Pusch. 2002. Bacterial abundance and production in river sediments as related to the biochemical composition of particulate organic matter (POM). Biogeochemistry 61: 37-55, doi:10.1023/A:1020298907014

Frenzel, P., B. Thebrath, and R. Conrad. 1990. Oxidation of methane in the oxic surface layer of a deep lake sediment (Lake Constance). FEMS Microbiol. Ecol. 73: 149-158, doi:10.1111/j.1574-6968.1990.tb03935.x

Gantzer, C. J., And H. G. Stefan. 2003. A model of microbial activity in lake sediments in response to periodic watercolumn mixing. Water Res. 37: 2833-2846, doi:10.1016/ S0043-1354(03)00110-6

Gantzer, P. A., L. D. Bryant, and J. C. Little. 2009a. Effect of hypolimnetic oxygenation on oxygen depletion rates in two water-supply reservoirs. Water Res. 43: 1700-1710, doi:10.1016/j.watres.2008.12.053

$\longrightarrow,-$ AND $-2009 \mathrm{~b}$. Controlling soluble iron and manganese in a water-supply reservoir using hypolimnetic oxygenation. Water Res. 43: 1285-1294, doi:10.1016/j. watres.2008.12.019

GLud, R. N. 2008. Oxygen dynamics of marine sediments. Mar. Biol. Res. 4: 243-289, doi:10.1080/17451000801888726 , P. Berg, H. Fossing, and B. B. Jørgensen. 2007. Effect of the diffusive boundary layer on benthic mineralization and $\mathrm{O}_{2}$ distribution: A theoretical model analysis. Limnol. Oceanogr. 52: 547-557.

, J. K. Gundersen, N. P. Revisbech, and B. B. Jørgensen. 1994. Effects on the benthic diffusive boundary layer imposed by microelectrodes. Limnol. Oceanogr. 39: 462-467.

, , H. RøY, AND B. B. JørGENSEN. 2003. Seasonal Importance of diffusion and fauna activity. Limnol. Oceanogr. 48: 1265-1276.
H. Stahl, P. Berg, F. Wenzhöfer, K. Oguri, and H. Kitazato. 2009. In situ microscale variation in distribution and consumption of $\mathrm{O}_{2}$ : A case study from a deep ocean margin sediment (Sagami Bay, Japan). Limnol. Oceanogr. 54: $1-12$.

Grant, H. L., R. W. Stewart, and A. Moilliet. 1962. Turbulence spectra from a tidal channel. J. Fluid Mech. 12: 241-268, doi:10.1017/S002211206200018X

Gundersen, J. K., AND B. B. JørGensen. 1990. Microstructure of diffusive boundary layers and the oxygen uptake of the sea floor. Nature 345: 604-607, doi:10.1038/345604a0

Higashino, M., C. J. Gantzer, and H. G. Stefan. 2004. Unsteady diffusional mass transfer at the sediment/water interface: Theory and significance for SOD measurement. Water Res. 38: 1-12, doi:10.1016/j.watres.2003.08.030

- B. L. O'Connor, M. Hondzo, and H. G. Stefan. 2008. Oxygen transfer from flowing water to microbes in an organic sediment bed. Hydrobiologia 614: 219-231, doi:10.1007/ s10750-008-9508-8

, And H. G. Stefan. 2005. Sedimentary microbial oxygen demand for laminar flow over a sediment bed of finite length. Water Res. 39: 3153-3166, doi:10.1016/j.watres.2005.05.032

Hondzo, M., T. Feyaerts, R. Donovan, and B. L. O'Connor. 2005. Universal scaling of dissolved oxygen distribution at the sediment-water interface: A power law. Limnol. Oceanogr. 50: $1667-1676$.

Jørgensen, B. B., And B. P. Boudreau. 2001. Diagenesis and sediment-water exchange, p. 211-244. In B. P. Boudreau and B. B. Jørgensen [eds.], The benthic boundary layer: Transport processes and biogeochemistry. Oxford Univ. Press.

, AND N. P. REvSBECH. 1985. Diffusive boundary layers and the oxygen uptake of sediments and detritus. Limnol. Oceanogr. 30: 111-122.

- , T. H. Blackburn, and Y. Cohen. 1979. Diurnal cycle of oxygen and sulfide microgradients and microbial photosynthesis in a cyanobacterial mat sediment. Appl. Environ. Microbiol. 38: 46-58.

Li, Y.-H., And S. Gregory. 1974. Diffusion of ions in sea water and in deep-sea sediments. Geochim. Cosmochim. Acta 38: 703-714, doi:10.1016/0016-7037(74)90145-8

Lorke, A., B. Müller, M. Maerki, And A. Wüest. 2003. Breathing sediments: The control of diffusive transport across the sediment-water interface by periodic boundary-layer turbulence. Limnol. Oceanogr. 48: 2077-2085.

- F. Peeters, And A. Wüest. 2005. Shear-induced convective mixing in bottom boundary layers on slopes. Limnol. Oceanogr. 50: 1612-1619.

— L L. Umlauf, T. Jonas, and A. Wüest. 2002. Dynamics of turbulence in low-speed oscillating bottom-boundary layers of stratified basins. Environ. Fluid Mech. 2: 291-313, doi:10.1023/A:1020450729821

Mackenthun, A. A., And H. G. Stefan. 1998. Effect of flow velocity on sediment oxygen demand: Experiments. J. Environ. Eng.-ASCE 124: 222-230, doi:10.1061/(ASCE)07339372(1998)124:3(222)

Müller, B., M. Maerki, C. Dinkel, R. Stierli, and B. Wehrli. 2002. In situ measurements in lake sediments using ionselective electrodes with a profiling lander system, p. 126-143. In M. Taillefert and T. F. Rozan [eds.], Environmental electrochemistry: Analyses of trace element biogeochemistry. ACS symposium series 811, American Chemical Society.

Münnich, M., A. Wüest, And D. M. Imboden. 1992. Observations of the second vertical mode of the internal seiche in an alpine lake. Limnol. Oceanogr. 37: 1705-1719. 
O'Connor, B. L., And J. W. Harvey. 2008. Scaling hyporheic exchange and its influence on biogeochemical reactions in aquatic ecosystems. Water Resour. Res. 44: W12423, doi:10.1029/2008WR007160

- AND M. Hondzo. 2008. Dissolved oxygen transfer to sediments by sweep and eject motions in aquatic environments. Limnol. Oceanogr. 53: 566-578.

Rasmussen, H., And B. B. JørGensen. 1992. Microelectrode studies of seasonal oxygen uptake in a coastal sediment: Role of molecular diffusion. Mar. Ecol. Prog. Ser. 81: 289-303, doi:10.3354/meps081289

Reichert, P. 1994. AQUASIM - a tool for simulation and data analysis of aquatic systems. Water Sci. Technol. 30: 21-30.

Røy, H., M. Huettel, And B. B. Jørgensen. 2004. Transmission of oxygen concentration fluctuations through the diffusive boundary layer overlying aquatic sediments. Limnol. Oceanogr. 49: 686-692.

Santschi, P., P. Höhener, G. Benoit, and M. Buchholtz-Ten BRINK. 1990. Chemical processes at the sediment-water interface. Mar. Chem. 30: 269-315, doi:10.1016/03044203(90)90076-O

Stachowitsch, M., B. Riedel, M. Zuschin, and R. Machan. 2007. Oxygen depletion and benthic mortalities: The first in situ experimental approach to documenting an elusive phenomenon. Limnol. Oceanogr. Methods 5: 344-352.
Veenstra, J. N., and S. L. Nolen. 1991. In situ sediment oxygen demand in five southwestern U.S. lakes. Water Res. 25: 351-354, doi:10.1016/0043-1354(91)90016-J

Wetzel, R. G. 2001. Limnology: Lake and river ecosystems, 3rd ed. Academic.

Wüest, A., And A. Lorke. 2003. Small-scale hydrodynamics in lakes. Annu. Rev. Fluid Mech. 35: 373-412, doi:10.1146/ annurev.fluid.35.101101.161220

, G. Piepke, and D. C. Van Senden. 2000. Turbulent kinetic energy balance as a tool for estimating vertical diffusivity in wind-forced stratified waters. Limnol. Oceanogr. 45: $1388-1400$.

WyngaARD, J. C., AND O. R. CotÉ. 1971. The budgets of turbulent kinetic energy and temperature variance in the atmospheric surface layer. J. Atmos. Sci. 28: 190-201, doi:10.1175/1520-0469 (1971)028<0190:TBOTKE $>2.0 . C O ; 2$

Zhang, H., W. Davison, and C. Ottley. 1999. Remobilisation of major ions in freshly deposited lacustrine sediment at overturn. Aquat. Sci. 61: 354-361, doi:10.1007/s000270050071

Associate editor: Ronnie Nøhr Glud

Received: 25 March 2009

Accepted: 26 October 2009

Amended: 10 December 2009 